\title{
Single polymer laminate composites by compression molding of knitted textiles and microparticles of polyamide 6: Preparation and structure- properties relationship
}

\author{
Shafagh D. Tohidi ${ }^{\mathrm{a}}$, Ana Maria Rocha ${ }^{\mathrm{a}, *}$, Nadya V. Dencheva ${ }^{\mathrm{b}}$, Zlatan Denchev ${ }^{\mathrm{b}}$ \\ ${ }^{\text {a }}$ Center of Textile Science and Technology (2C2T), Department of Textile Engineering, University of Minho, Guimarães, Portugal \\ $\mathrm{b}$ i3N - Institute for Polymers and Composites, Department of Polymer Engineering, University of Minho, Guimarães, Portugal
}

\section{A R T I C L E I N F O}

\section{Keywords:}

Single polymer composite

Polyamide 6

Knitted textile reinforcements

Tensile properties

\begin{abstract}
A B S T R A C T
Knitted reinforced single polymer laminate composites based on polyamide 6 (KSPCS $\left.S_{P A 6}\right)$ were produced by compression molding of polyamide 6 microparticles $\left(M P_{S_{P A 6}}\right)$ powder-coating annealed PA6 Rib or Jersey knitted textile structures. The $M P S_{P A 6}$ were synthesized by solution/precipitation activated anionic ring-opening polymerization of $\varepsilon$-caprolactam. The tensile properties of $K S P C S_{P A 6}$ were studied in relation to the knitted reinforcement architecture, fiber volume fraction, ply orientation and stacking orders. The tensile stiffness and strength of the newly prepared $K S P C S_{P A 6}$ with fiber content of $15 \%$ showed significant improvements as compared to the neat anionic PA6 matrix and to commercial hydrolytic PA6 (HPA6). The mechanical behavior of the $K_{S P C S_{P A 6}}$ was correlated with the geometry parameters of the knitted reinforcements, the polymorph content of the samples and their crystallinity indexes determined by differential scanning calorimetry and wide-angle X-ray diffraction. The fracture behavior of $K_{S P C S_{P A 6}}$ was investigated by electron microscopy complemented by simulation studies.
\end{abstract}

\section{Introduction}

The single polymer composites (SPCS) wherein both matrix and reinforcements are made from the same polymer were introduced several decades ago by Capiati and Porter [1]. With time the SPCs concept was extended to almost all commercial polymers. Exhaustive and recent reviews on the SPCs preparation, morphology, and mechanical behavior are available [1-3]. SPCs based on semicrystalline polymers are most frequently studied although amorphous-amorphous or amorphous-semicrystalline systems have been described as well [4]. The fact that in SPCs both matrix and the reinforcements are made of the same polymer has two constructive effects: (i) increases the interfacial adhesion due to the possibility of H-bonds or even covalent bonding across the interface $[5,6]$ and (ii) turns the composite fully recyclable by reprocessing, i.e., a clear positive environmental effect is present [7]. The most widely used method for preparation of SPCs is hot compaction of fibers, in which partial melting of their outer surface takes place thus forming the matrix. The inner part of the fibers does not melt, remains highly oriented and acts as reinforcement. In such a way, PA6-based single polymer composites $\left(S P C S_{P A 6}\right)$ are prepared comprising high volume fraction of reinforcing fibers, which is a clear advantage of this method [8-10]. Its major drawback is that, due to the identity of the matrix and the reinforcement materials, the processing window does not exceed several degrees and even the slightest overheating of the fibers irreversibly degrades its reinforcing properties.

Attempts were made to widen the processing window of the conventional techniques for SPCs preparation. In-situ creation of the matrix by a polymerization process carried out in the presence of the reinforcement is among the possible solutions for $S P C S_{P A 6}[11,12]$. Activated anionic ring-opening polymerization (AAROP) of inexpensive lactams is a possible reaction pathway. In this way Gong et al [12] prepared SPCs consisting of in-situ formed PA6 matrix reinforced with PA6 plain woven fabric using a reactive injection molding (RIM) processing procedure. The optimum polymerization temperature was $160{ }^{\circ} \mathrm{C}$, thus permitting for a wide processing window of ca. $65^{\circ} \mathrm{C}$. As a result, tensile strengths of $150 \mathrm{MPa}$ of the final laminate were achieved. Subsequent work by Dencheva et al [13] described the preparation and the properties of $S P C S_{P A 6}$ via in-mold AAROP using a semiautomatic prototype RIM equipment [14]. The AAROP temperature was $160^{\circ} \mathrm{C}$ resulting in $S P C S_{P A 6}$ samples with tensile strength of above $130 \mathrm{MPa}$, using only $15-20 \mathrm{wt} \%$ of fibers. In these $S P C S_{P A 6}$ impact strengths up to three times higher than the neat anionic PA6 were registered, accompanied by a 30 to $60 \%$ increase of the tensile strength. The Young modulus of these textile-reinforced samples, however, dropped by 30 to

\footnotetext{
* Corresponding author.

E-mail address: amrocha@det.uminho.pt (A.M. Rocha).
} 
$50 \%$ as compared to the neat anionic PA6 matrix.

The geometry of the reinforcing fibrous structure plays a significant role in determining the mechanical properties of the textile-reinforced laminate composites [15]. Studies on the influence of the knitted architecture on final mechanical behavior of laminate composites demonstrated that the loop length, fiber crossover points and relative fiber distribution along the two principal loading axes led to microstructural imperfections, followed by tensile failure [16-19]. Moreover, the highest elastic modulus and tensile strength were depicted when the loops were perfectly aligned parallel to the wale direction of the fabric [20].

In the present study $S P C S_{P A 6}$ were produced, for the first time, via compression molding of various plies of commercial PA6 textile structures with either Rib or Jersey knitted architectures that were powdercoated with PA6 microparticles $\left(M P_{S_{P A 6}}\right)$, previously synthesized by means of AAROP of ECL in solution. The processing window for compression molding in this case was expected to be significantly broader than in most of the SPCs prepared by melt processing. An attempt was made to assess the influence of the geometry parameters (e.g., knitted loop size and arrangement) of the knitted textile structures on the tensile properties of the novel $\operatorname{KSPC}_{P A 6}$. The latter were related to the modes of fracture under off-axial load conditions, the $\alpha-/ \gamma$-polymorph structure, the thermal properties and the crystallinity index of the samples containing various amounts and types of knitted fabrics.

\section{Experimental and test methods}

\subsection{Materials}

Rib and Jersey fabrics prepared from air jet textured PA6 continuous filament yarns (160 dtex) commercialized by QTT, Portugal were employed in this study as reinforcements. To minimize contaminations, all the textile structures were pre-washed with the same type of non-ionic detergent solution at $30^{\circ} \mathrm{C}$ for $30 \mathrm{~min}$ and then rinsed with reverse osmosis water for another $15 \mathrm{~min}$. All knitted reinforcements were immersed in acetone for $30 \mathrm{~min}$ and subsequently dried for $2 \mathrm{~h}$ at $60^{\circ} \mathrm{C}$, to eliminate any non-chemically bonded hydrophobic finish from the filament surface. To optimize the mechanical properties of the PA6 knitted textiles, all of them were stretched to $30 \%$ of their original length along the two principal directions, using a screen stretching apparatus (Fig. 1a). Once stretched, the reinforcements were annealed with fixed ends at $170{ }^{\circ} \mathrm{C}$ for $90 \mathrm{~min}$ using a specially designed metal frame (Fig. 1b). All the annealed knitted reinforcements developed larger empty spaces between the knitted loops upon stretching (Fig. 1c and d).

Table 1 shows the sample designation, areal weight and thickness of knitted reinforcements before and after the washing/drying/annealing cycle designated as "treatment". The remarkable variances in the areal weight of R and R-A structures are attributable to a structural difference that allows the Rib architecture to extend more and reach significantly lower areal weight than the Jersey.

All the solvents in this work ("purum" grade) were obtained from Sigma Aldrich and used as received. The ECL monomer with reduced moisture content suitable for AAROP was delivered by Brüggemann Chemical, Germany. Before use, it was kept under vacuum for $1 \mathrm{~h}$ at $23^{\circ} \mathrm{C}$. As polymerization activator, Bruggolen C20P (C20) from Brüggemann Chemical, Germany was applied. According to the manufacturer data, C20 contains $80 \mathrm{wt} \%$ of blocked diisocyanate in ECL. The initiator sodium dicaprolactamato- bis-(2-methoxyethoxo)-aluminate $(80 \mathrm{wt} \%$ in toluene, DL) was purchased from Katchem and used without further treatment.

\subsection{Ssynthesis of PA6 microparticles by AAROP}

The polyamide 6 microparticles $\left(M P_{P_{P A 6}}\right)$ were produced by solution-precipitation AAROP of ECL performed as described in detail previously [21,22]. The ECL monomer was dissolved in a $1: 1 \mathrm{v} / \mathrm{v}$ toluene/xylene mixture under nitrogen atmosphere and under reflux and then the components of the catalytic system DL and C20 were introduced. After reaction time of $1 \mathrm{~h}$ at $125-135^{\circ} \mathrm{C}$ under constant stirring, the anionic $M P_{S_{P A 6}}$ were produced in the form of fine powder that was separated from the reaction mixture by vacuum filtration, washed with methanol and dried. The average viscometric molecular weight $M_{v}$ of the as-prepared $M P S_{P A 6}$ was measured in $97 \%$ sulfuric acid at a concentration of $0.2 \mathrm{~g} / \mathrm{dL}$ with a suspended level Ubbelohde viscometer at $25^{\circ} \mathrm{C}$. The Mark-Houwink equation for PA6 was used with $K=5.066 \cdot 10^{-4}$ and $\alpha=0.74$ [23]. A $M_{v}$ of $36,500 \mathrm{~g} / \mathrm{mol}$ was determined for $M P_{S_{P A 6}}$, which was slightly below the values or the Rib and
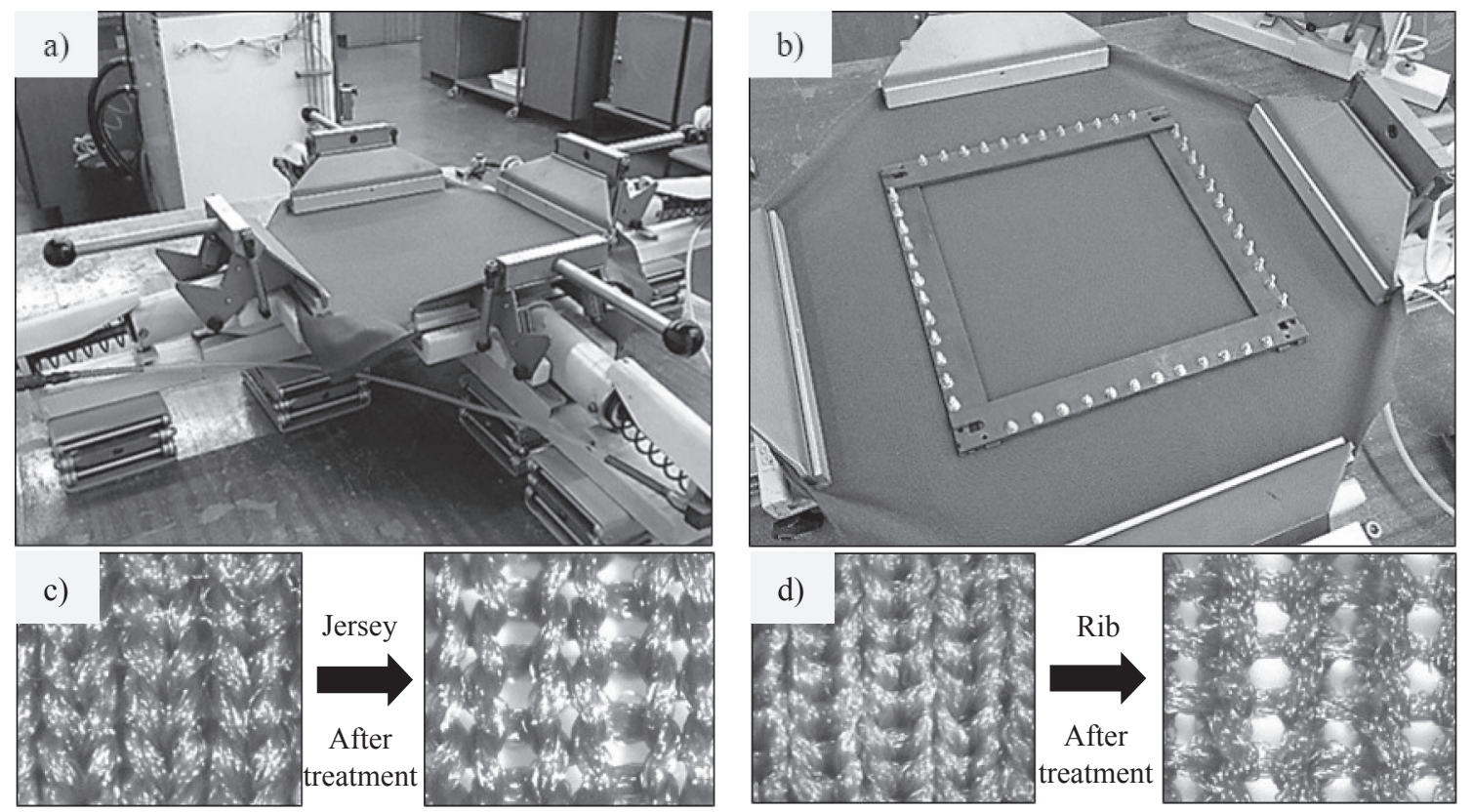

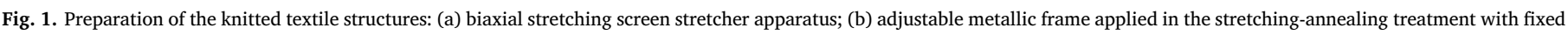
ends; Structural deformation after stretching-annealing treatment of (c) Jersey; (d) Rib knitted reinforcements. 
Table 1

Sample designation and properties of weft knitted reinforcements.

\begin{tabular}{|c|c|c|c|c|c|c|}
\hline Reinforcement type & Treatment & Sample Designation & WPC $(1 / \mathrm{cm})^{\mathrm{a}}$ & CPC $(1 / \mathrm{cm})^{\mathrm{a}}$ & Areal weight $\left(\mathrm{g} / \mathrm{m}^{2}\right)$ & Thickness (mm) \\
\hline \multirow[t]{2}{*}{ Rib } & - & $\mathrm{R}$ & 16 & 25 & $208 \pm 4$ & $0.79 \pm 0.01$ \\
\hline & + & $\mathrm{R}-\mathrm{A}$ & 13 & 18 & $108 \pm 2$ & $0.60 \pm 0.01$ \\
\hline \multirow[t]{2}{*}{ Jersey } & - & $\mathrm{J}$ & 16 & 30 & $160 \pm 4$ & $0.54 \pm 0.01$ \\
\hline & + & J-A & 15 & 25 & $102 \pm 2$ & $0.41 \pm 0.01$ \\
\hline
\end{tabular}

${ }^{\mathrm{a}} \mathrm{WPC}=$ Wale per centimeter and CPC $=$ Course per centimeter.

Jersey textile reinforcements with $M_{v}$ of ca. $39,500 \mathrm{~g} / \mathrm{mol}$. More details about the structure, morphology and properties of the $M P S_{P A 6}$ without and with various payloads can be found elsewhere [21,22,24,25].

\subsection{Preparation of $\mathrm{KSPC}_{\mathrm{PA} 6}$ by compression molding}

The $K S P C s_{P A 6}$ of this study were prepared by compression molding of Rib or Jersey PA6 knitted textile plies between which desired amounts of anionic $M{ } S_{P A 6}$ were placed. For the preparation of $K S P C S_{P A 6}$ composites of $k$ plies, the respective amounts of $M P S_{P A 6}$ were divided into $(k+1)$ equal portions that were put between the textile plies. Then, consolidation of the ply sets by compression molding was performed in a Moore hydraulic hot press using a mold with dimensions $70 \times 70 \times 2 \mathrm{~mm}^{3}$. The pressure applied was $5 \mathrm{MPa}$ for $10 \mathrm{~min}$ at $215^{\circ} \mathrm{C}$ - a temperature below the $T_{m}$ of the PA6 knitted reinforcements and above that of the $M P_{S_{P A 6}}$, and the samples were subsequently cooled down to $50^{\circ} \mathrm{C}$ at a rate of ca. $40 \mathrm{C} / \mathrm{min}$. In such a way $\mathrm{KSPCS}_{P A 6}$ with three fiber contents were prepared, i.e., $15 \%, 20 \%$ and $25 \%$. The necessary number of textile plies for each $V_{f}$ value was determined according to Eq. (1) $[26,27]$.

$V_{f},(\%)=\frac{A_{w} \cdot N}{\rho_{f} \cdot t} \times 100$

wherein $A_{w}\left(\mathrm{~g} / \mathrm{m}^{2}\right)$ is the area density of the textile reinforcement, $N$ is the number of plies, $\rho_{f}$ is the density of the PA6 fibers $\left(1.13, \mathrm{~g} / \mathrm{m}^{3}\right)$ and $t$ in $(\mathrm{m})$ is the laminate thickness. The knitted reinforcements were stacked unidirectionally or in different directions. To obtain the best fit to the mold thickness of $2 \mathrm{~mm}, 20 \%$ fiber content were used corresponding to four plies of Rib or five plies of Jersey reinforcements. Two additional fiber contents of 15 and $25 \%$ were also chosen. Table 2 demonstrates all samples studied in this work and explains their designations. The attempts to increase the fiber fraction to $30 \%$ and more were resulted in rupture of the upper textile plies.

\subsection{Morphological characterization}

Olympus BH-2 light microscope equipped with Leica Application

Table 2

The designation of laminate $\mathrm{KSPCS}_{P A 6}$ composites.

\begin{tabular}{lllll}
\hline $\begin{array}{l}\text { KSPCS } \\
\text { designation }\end{array}$ & $\begin{array}{l}\text { Knitted reinforcement } \\
\text { architecture }\end{array}$ & $V_{f}(\%)$ & $\begin{array}{l}\text { Plies } \\
\text { Number }\end{array}$ & Plies Orientation \\
\hline PU-J $\left({ }^{\mathrm{a}}\right)-15$ & Jersey, after & 15 & 3 & Unidirectional $^{\mathrm{a}}$ \\
PU-J $\left({ }^{\mathrm{a}}\right)-20$ & stretching and & 20 & 5 & \\
PU-J $\left({ }^{\mathrm{a}}\right)-25$ & annealing & 25 & 6 & \\
PM-J $\left({ }^{\mathrm{b}}\right)-15$ & & 15 & 3 & Multidirectional $^{\mathrm{b}}$ \\
PU-R( $\left({ }^{\mathrm{a}}\right)-15$ & Rib, after stretching & 15 & 3 & Unidirectional $^{\mathrm{a}}$ \\
PU-R $\left({ }^{\mathrm{a}}\right)-20$ & and annealing & 20 & 4 & \\
PU-R $\left({ }^{\mathrm{a}}\right)-25$ & & 25 & 5 & Multidirectional $^{\mathrm{b}}$ \\
PM-R $\left({ }^{\mathrm{b}}\right)-15$ & & 15 & 3 & \\
\hline
\end{tabular}

${ }^{a}$ Unidirectional laminating of Knitted textile reinforcements in which 0 is for walewise and 90 for course-wise directions.

${ }^{\mathrm{b}}$ Multidirectional laminating of Knitted textile reinforcements via combination of wale (0), course (90) and diagonal (45) orientations. In these samples, the designations of (0) and (90) represent the stacking orders of $0 / 45 / 0$ and $90 / 45 / 90$, respectively.
Suite 4 software was employed to visualize and analyze optical microscopy images of $K_{S P C S_{P A 6}}$ studying the distribution of plies in samples prepared by microtoming. The scanning electron microscopy (SEM) studies were performed in a NanoSEM-200 apparatus of FEI Nova (USA) using mixed secondary electron/back-scattered electron inlens detection. $\mathrm{Au} / \mathrm{Pd}$ alloy was used to sputter-coat the samples to be observed.

The differential scanning calorimetry (DSC) measurements were carried out in a $200 \mathrm{~F} 3$ equipment of Netzsch at a heating rate of $10^{\circ} \mathrm{C} /$ min under nitrogen purge. To remove the thermal history of the specimens, two consecutive heating scans were performed, whereby the crystallization between them was made with a cooling rate of $10^{\circ} \mathrm{C} /$ min. The temperature of glass transition $T_{g}$ of the samples, the melting temperatures $T_{m}$ and the DSC crystallinity index were obtained for each sample. The typical sample weights were in the $5-15 \mathrm{mg}$ range. The DSC crystallinity index $X_{C}$ (\%) of the samples was calculated according to Eq. (2):

$X_{c}^{D S C},(\%)=\frac{\Delta H_{m}^{i}}{\Delta H_{m}{ }^{\circ}}$

where the $\Delta H_{m}^{i}$ is the registered melting enthalpy of the current sample and $\Delta H_{m}{ }^{\circ}$ is the melting enthalpy of a $100 \%$ crystalline PA6 $(230 \mathrm{~J} / \mathrm{g})[28,29]$.

All WAXS patterns were collected in a Bruker D8 Discover $\theta-\theta$ diffractometer working with $\mathrm{Cu} K \alpha$ radiation $(\lambda=1.541 \AA$ ). XRD patterns were collected in the $2 \theta$ range of $5-45^{\circ}$ with a step time of $2 \mathrm{~s}$ and step size of $0.1 \mathrm{deg} / \mathrm{min}$. Curve fitting of the XRD patterns was made as previously shown [30] using a commercial peak-fitting software. The XRD crystallinity index $X_{c}^{X R D}$ was calculated according to:

$X_{c}^{X R D},(\%)=\frac{\sum A_{c}}{\sum A_{c}+\sum A_{a}}$

where $\sum_{c}^{A}$ is the integrated area underneath the respective crystalline peaks and $\sum_{a}^{A}$ is the integrated area of the amorphous halo(s).

\subsection{Mechanical characterization}

The mechanical tests in tension were performed in an Instron 4505 testing machine at $23 \pm 2{ }^{\circ} \mathrm{C}$ with a standard load cell of $50 \mathrm{KN}$ and at a constant crosshead speed of $2 \mathrm{~mm} / \mathrm{min}$. Conditioned PA6 laminate composites were used, stored for ca. 30 days at $23^{\circ} \mathrm{C}$ and $65 \%$ relative humidity. Normalized test specimens were cut by laser from one and the same composite plate. $K_{S P C S_{P A 6}}$ specimens were shaped according to ASTM D638 with a gauge length of $38 \mathrm{~mm}$. At least five specimens of each sample were studied to calculate the average values and their standard deviation. The Young's modulus (E) was calculated from the stress-strain curves as the tangent at $0-1 \%$ strain. For the tensile tests of knitted reinforcement, the method of ASTM D5034 (grab test) was adopted performed in the same Instron 4505 machine. The $150 \times 100$ $\mathrm{mm}^{2}$ annealed knitted samples after stretching and annealing at $170{ }^{\circ} \mathrm{C}$ for $90 \mathrm{~min}$ were stored for $5 \mathrm{~h}$ in a controlled environment at $23^{\circ} \mathrm{C}$ for at least $5 \mathrm{~h}$ before testing.

Ultimately, some modelling and simulation experiments were performed with annealed Rib and Jersey structures using AutoCAD (Auto 

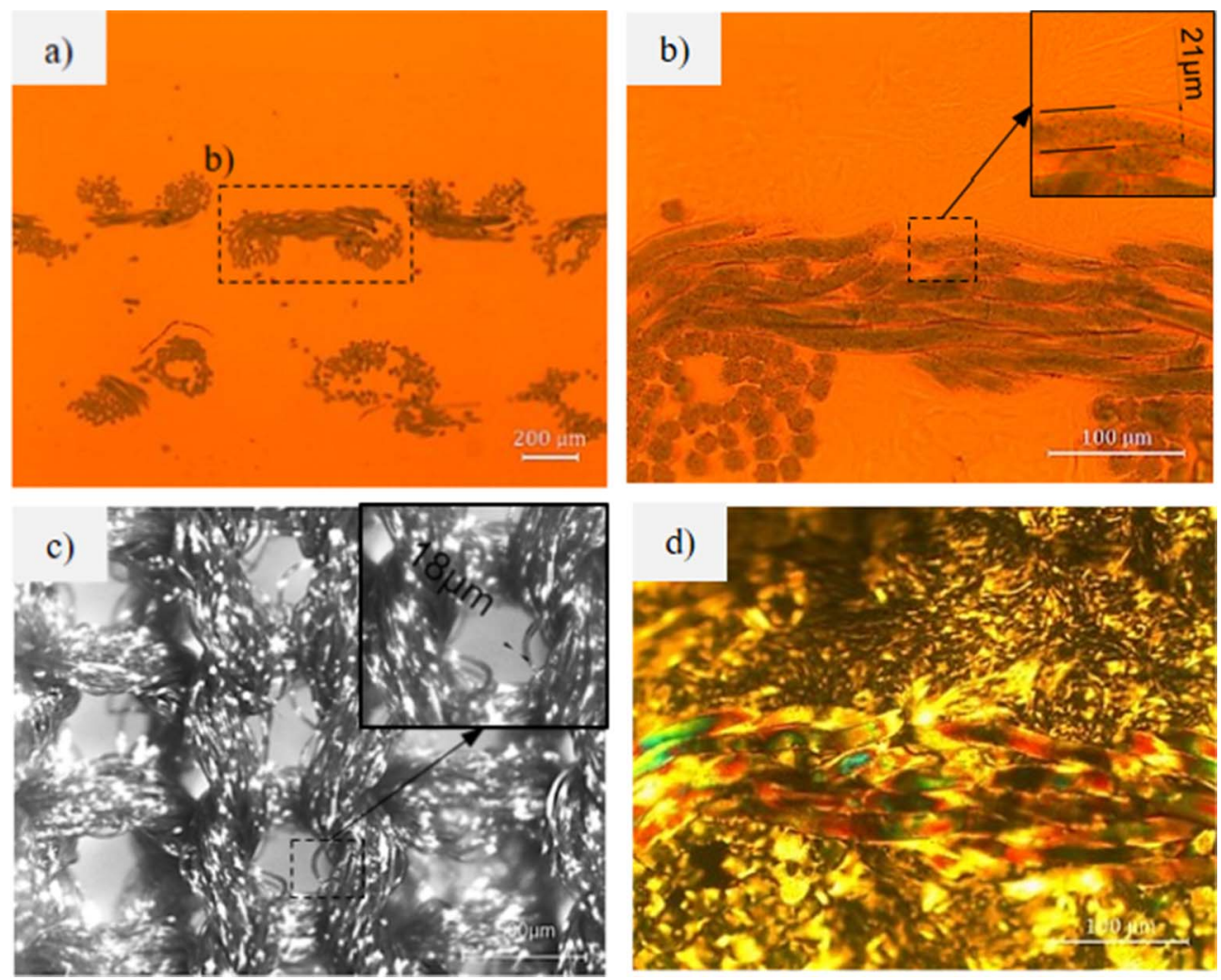

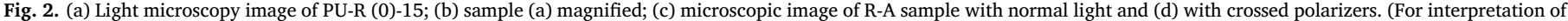
the references to colour in this figure legend, the reader is referred to the web version of this article.)
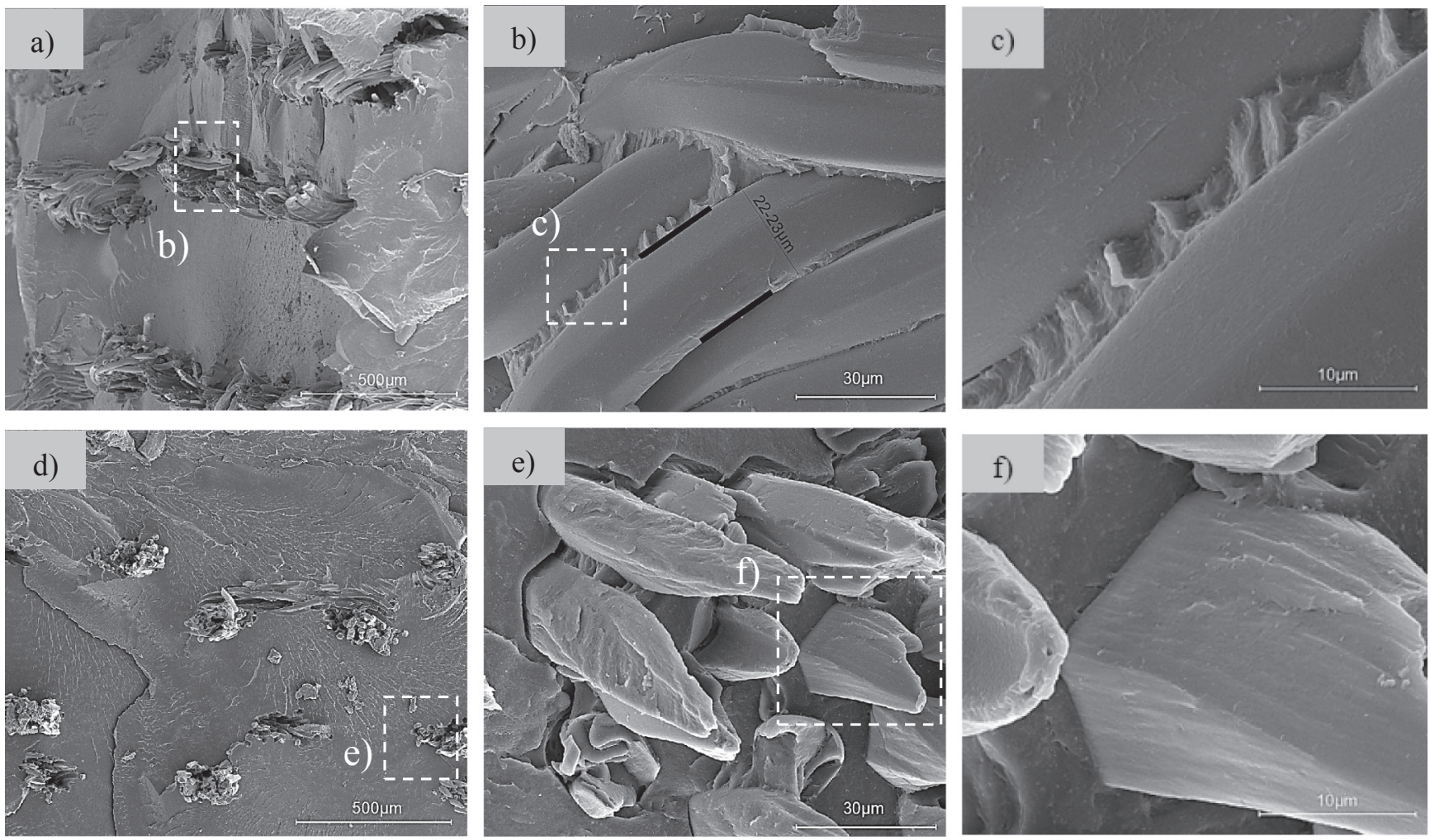

Fig. 3. SEM images after cryofracture of PU-R15 composite; (a-c) course direction (d-f) wale direction. 
Desk Inc., USA, version 2014) and SolidWorks (Dassault Systems, France, version 2014) software to correlate structural analysis of annealed knitted reinforcements with the final tensile properties of $\operatorname{KSPCS}_{P A 6}$.

\section{Results and discussion}

\subsection{Microscopy studies of KSPCS ${ }_{P A 6}$}

Polarizing light microscopy and scanning electron microscopy were used to characterize the $K_{S P C S_{P A 6}}$ materials and their components. Fig. 2a shows the PLM micrographs of the PU-R(0)-15 sample in which a Rib knitted loop is embedded in the matrix material. Notably, the PA6 filaments from the textile structure do not show any sign of melting that would deform their circular cross-sections. Moreover, a close visual inspection of the latter and of the longitudinally cut monofilaments reveals refractive index differences between the core of some textile PA6 monofilaments and their surface, suggesting the presence of a transcrystalline layer (TCL) (Fig. 2b). This TCL is expected to develop during the compression molding because of the epitaxial crystallization of anionic PA6 material from the matrix upon the oriented PA6 filaments of the textile structure. Such a phenomenon was observed and studied earlier obtained by reactive injection molding [13]. As seen from both pictures in Fig. $2 \mathrm{~b}$ and $\mathrm{c}$, the average thickness of the textile monofilament embedded in the KSPCS $S_{P A 6}$ material measured by $22-23 \mu \mathrm{m}$, whereas in the annealed knitted structures, it was $17-18 \mu \mathrm{m}$. This difference is an indirect proof for the formation of TCL with a supposed thickness of 3-6 $\mu \mathrm{m}$. Fig. 2d illustrates a micrograph of the same PU-R(0)-15 sample with crossed polarizers, which allows the observation of the isotropic matrix (not birefringent) and the birefringent oriented monofilaments displaying existence of orientationdependent differences in refractive index, i.e., different superficial color in wale and course directions.

The textile/matrix interface and microstructure were studied additionally by SEM. Fig. 3 shows representative micrographs of the PU-R15 sample cryogenically fractured along the wale (0) (Fig. 3a-c) and course (90) directions (Fig. 3d-f). It appears that the textile reinforcements are well embedded between relatively thick matrix layers. The monofilaments of the textile structure possess visible diameters of $22-23 \mu \mathrm{m}$, which confirms the data of light microscopy and supports indirectly the hypothesized TCL formation. The thickness of this layer seems to be between 3 and $6 \mu \mathrm{m}$. The filaments that can be observed in their longitudinal direction show no sign of melting or surface degradation. The images with higher magnification of this series (Fig. 3b and c) showed that the anionic PA6 matrix material has penetrated deeply between the monofilaments wetting them well and leaving no visible voids or cracks. Therefore, a strong adhesion at the matrix-fiber interface may be expected. Larger magnifications (Fig. 3c-f) demonstrated that the fractured filaments have conical shapes. This is an indication of strong adhesion between the reinforcing filaments and the matrix that forced the filaments to carry the load and break rather than to be pulled out of the matrix. All these effects should be related to the chemical identity of both matrix and reinforcement materials, as well as to the similarity in physical properties related to their melting/recrystallization behavior.

\subsection{DSC studies}

A parameter of prime importance for the compression molding of $K_{S P C S_{P A 6}}$ is the width of the processing window (PW). It can be determined by the difference in the melting temperatures $\left(\mathrm{T}_{\mathrm{m}}\right)$ of the matrix and reinforcements materials. Thus, Fig. $4 \mathrm{a}$ and $\mathrm{b}$ displays the first and second heating scans respectively performed at $10{ }^{\circ} \mathrm{C} / \mathrm{min}$. A PW width of ca. $16-17^{\circ} \mathrm{C}$ can be determined in Fig. $4 \mathrm{a}$, which is significantly higher than that previously found for $\operatorname{KSPCS}_{P A 6}$ [31]. This fact, as evidenced by the microscopy observations above, apparently solves the problem of the undesirable fusion of the reinforcements during the compression molding. Fig. 4a confirmed that the $\mathrm{T}_{\mathrm{m}}$ of $M{ } S_{P A 6}$ is $207-208^{\circ} \mathrm{C}$, while those of R, R-A and J-A textile reinforcements vary in the $223-224^{\circ} \mathrm{C}$ range. This observation could be explained with the already mentioned small size of the highly porous anionic $M P_{S_{P A 6}}$. The absence of side reactions during AAROP leading to cross-linking [32] can explain the inferior $\mathrm{T}_{\mathrm{m}}$ of anionic $M P S_{P A 6}$. The slightly lower $M_{v}$ values in comparison with the Rib and Jersey textile reinforcements should act in the same direction.

The curves of the first heating show also that the two knitted textile reinforcements displayed some broad low-temperature endothermic peaks centered at $75^{\circ} \mathrm{C}$ (Fig. 4a, curves 1-3) that remained not affected by the annealing with fixed ends at $170{ }^{\circ} \mathrm{C}$ for $90 \mathrm{~min}$, i.e., below the $\mathrm{T}_{\mathrm{m}}$ of the textile. Since this feature disappeared completely during the second scan performed with completely molten textiles (Fig. 4b, curves $1-3)$, it was associated to a relaxation processes within the knitted structure occurring right above glass transition temperature $T_{g}$. The low-temperature peak of the $M P_{S_{P A 6}}$ during the first DSC scan centered at ca. $100^{\circ} \mathrm{C}$ could be removed by heating below melting temperature and was therefore related with the release of the humidity absorbed by the porous micron-sized $M P_{P A 6}$.

The DSC curves in Fig. $4 \mathrm{~b}$ reveal the $\mathrm{T}_{\mathrm{g}}$ of all samples that were covered during the first scan by the lower temperature endotherm. In the two textile structures before and after annealing the $T_{g}$ values lie between 56 and $57^{\circ} \mathrm{C}$, while the $\mathrm{T}_{\mathrm{g}}$ of the $M{ } S_{P A 6}$ was found to be $33^{\circ} \mathrm{C}$. This observation indicates higher segmental mobility of the polymer chains in the anionic $M P S_{P A 6}$ as compared to those in the knitted textile reinforcements. The maxima of the melting endotherms during the second scan for the knitted structures coincided with those of the first scan being all centered at $223-224^{\circ} \mathrm{C}$. Notably, a low temperature shoulder in the $212-214^{\circ} \mathrm{C}$ appears in these samples during the second scan (Fig. 4b curves 1-3) attributable to the melting of the $\gamma$-PA6 polymorph, while the $\mathrm{T}_{\mathrm{m}}$ values above $220^{\circ} \mathrm{C}$ should be related to the $\alpha$ PA6 polymorph [33-35]. The molten $M P_{S_{P A 6}}$ displayed a $\mathrm{T}_{\mathrm{g}}$ of $210^{\circ} \mathrm{C}$ being with $3^{\circ} \mathrm{C}$ higher than that during the first scan (Fig. 4a, curve 4). This curve shows also a weak shoulder below $200^{\circ} \mathrm{C}$ that could be related with the melting of some amounts of anionic $\gamma$-PA6.

Fig. 5 displays the DSC traces of laminate $K S P C S_{P A 6}$ reinforced by uni- and multi-directional orientation of the knitted textile plies (curves 2-5) compared to that of an anionic PA6 sample produced by compression molded $M P S_{P A 6}$ (Fig. 5, curve 1).

The anionic neat PA6 obtained from compression molded $M P S_{P A 6}$ (denominated as $\mathrm{PN}$ ) displayed as expected a single melting peak at $\mathrm{T}_{\mathrm{m}}=210^{\circ} \mathrm{C}$ and a $\mathrm{T}_{\mathrm{g}}$ transition at $40^{\circ} \mathrm{C}$. These data are consistent with those obtained previously in the DSC studies of neat $M P_{S_{P A 6}}$ [21]. In the $K_{S P C S_{P A 6}}$ with either uni- (Fig. 5 curves 2,3) and multi-directional knitted plies (Fig. 5 curves 4,5), a bimodal melting endotherm was registered with $\mathrm{T}_{\mathrm{m} 1}=208-210^{\circ} \mathrm{C}$ and $\mathrm{T}_{\mathrm{m} 2}=218-220^{\circ} \mathrm{C}$. This dual peak should be related with the melting of PA6 originating from the anionic PA6 matrix and from the hydrolytic PA6 textile reinforcements. It should be noted that while in the $K S P C S_{P A 6}$ with unidirectional textile plies PU-R-15 and PU-J-15 only one $\mathrm{T}_{\mathrm{g}}$ transition was clearly observed at ca. $33^{\circ} \mathrm{C}$ related to the anionic matrix, in the samples with multidirectional ply orientation PM-R-15 and PM-J-15, the $\mathrm{T}_{\mathrm{g}}$ of both matrix and reinforcement PA6 were detected at $34-36^{\circ} \mathrm{C}$ and $48-49^{\circ} \mathrm{C}$, respectively. It seems that the ply orientation in the $K S P C S_{P A 6}$ of this study may affect the chain mobility of the reinforcing PA6 material.

Based on the DSC traces, the crystallinity indices $X_{c}^{D S C}$ of all $K_{S P C S_{P A 6}}$ and their precursors were calculated according to Eq. (2) and presented in Table 3. The $M P_{S_{P A 6}}$ and the anionic PA6 obtained by their compression molding (PN) possess quite low $\mathrm{T}_{\mathrm{g}}$ values of ca. $33^{\circ} \mathrm{C}$ and $\mathrm{T}_{\mathrm{m}}$ varying between 208 and $210^{\circ} \mathrm{C}$. The $\mathrm{X}_{\mathrm{c}}^{\mathrm{DSC}}$ of PN becomes lower than that of $M P_{P A 6}$ most probably due to the relatively faster cooling down during the compression molding. The stretching/annealing of fixed ends of both textile reinforcement types increased their crystallinity index with up to $10 \%$, maintaining the $\mathrm{T}_{\mathrm{g}}$ and $\mathrm{T}_{\mathrm{m}}$ values in the 

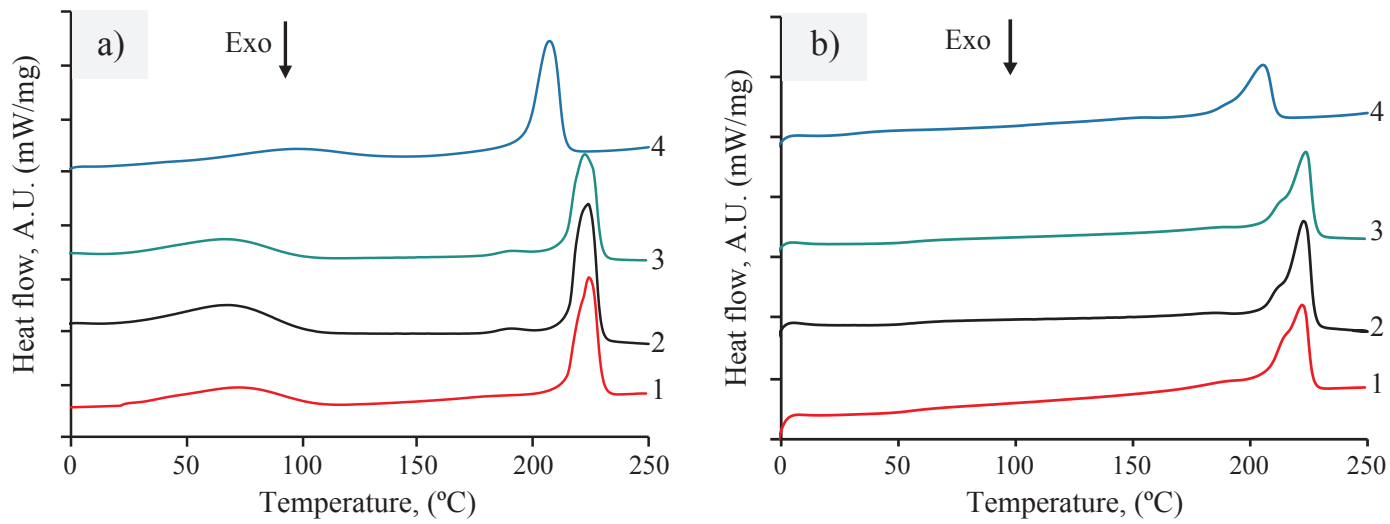

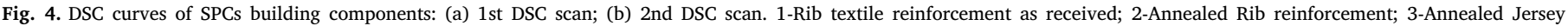
reinforcement; 4-Anionic $M P_{S_{P A 6}}$. (For interpretation of the references to colour in this figure legend, the reader is referred to the web version of this article.)

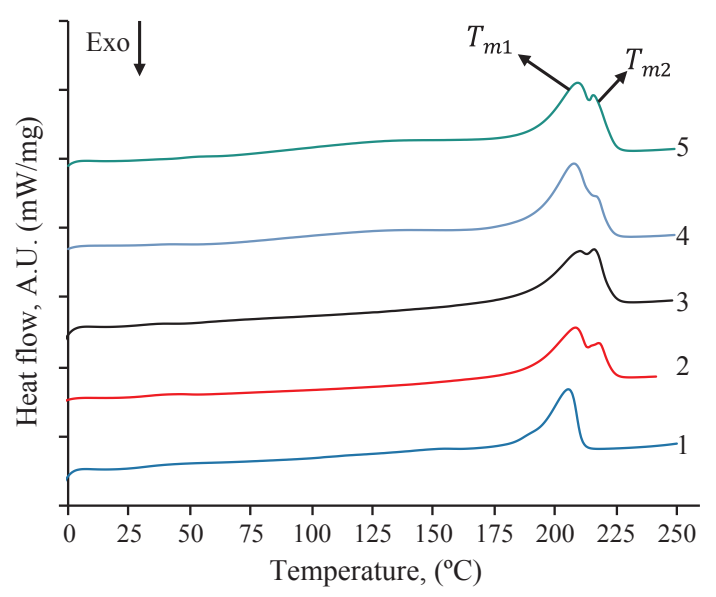

Fig. 5. DSC curves of KSPCSPA6 from hot compacted MPSPA6-coated knitted textile structures: 1-PN; 2-PU-R15; 3-PU-J15; 4-PM-R15; 5-PM-J15. For sample designation see Table 2. (For interpretation of the references to colour in this figure legend, the reader is referred to the web version of this article.)

Table 3

Crystallinity index $X_{c}^{D S C}$ for SPCs and their precursors. For sample designations see Table 2.

\begin{tabular}{lllll}
\hline Sample designation & $T_{g}\left({ }^{\circ} \mathrm{C}\right)$ & $T_{m 1}\left({ }^{\circ} \mathrm{C}\right)$ & $T_{m 2}\left({ }^{\circ} \mathrm{C}\right)$ & $X_{c}^{D S C}, \%^{\mathrm{a}}$ \\
\hline$M P_{P A 6}$ & $32.3^{\mathrm{a}}$ & 207.8 & - & 34.9 \\
PN & 33.3 & 210.0 & - & 27.5 \\
$\mathrm{R}$ & $55.3^{\mathrm{a}}$ & - & 224.2 & 34.7 \\
$\mathrm{~J}$ & $56.2^{\mathrm{a}}$ & - & 224.5 & 35.0 \\
$\mathrm{~J}-\mathrm{A}$ & $57.0^{\mathrm{a}}$ & - & 223.5 & 41.9 \\
R-A & $56.5^{\mathrm{a}}$ & - & 223.2 & 46.0 \\
PU-J-15 & 30.3 & 210.2 & 216.5 & 31.0 \\
PU-J-20 & 43.5 & 209.8 & 219.1 & 30.7 \\
PU-J-25 & 41.1 & 209.2 & 219.3 & 30.0 \\
PM-J-15 & 46.5 & 210.2 & 215.7 & 34.7 \\
PU-R-15 & 32.3 & 208.2 & 217.8 & 30.9 \\
PU-R-20 & 33.4 & 208.6 & 215.0 & 33.2 \\
PU-R-25 & 32.6 & 208.2 & 216.9 & 33.6 \\
PM-R-15 & 37.5 & 208.2 & 216.2 & 33.6 \\
\hline
\end{tabular}

${ }^{\text {a }} T_{g}$ determined during the 2nd DSC scan.

ranges of $55-57^{\circ} \mathrm{C}$ and $223-224^{\circ} \mathrm{C}$, respectively. Therefore, the DSC data in Table 3 prove that the anionic PA6 matrix material and the hydrolytic oriented PA6 of the reinforcements are quite distinct in their physical properties, being at the same time chemically identical.

Each $K_{S P C S_{P A 6}}$ material in Table 3 displayed clear bimodal character of the melting endotherms (all obtained during the 1st DSC scan). It is logical to attribute the first $\mathrm{T}_{\mathrm{m} 1}$ to the PA6 of the matrix and the second $\mathrm{T}_{\mathrm{m} 2}$ to that of the higher melting temperature of the knitted textile reinforcement. While the $\mathrm{T}_{\mathrm{m} 1}$ values almost coincide with that of the $M P S_{P A 6}$ and PN, the $\mathrm{T}_{\mathrm{m} 2}$ values of all $K S P C S_{P A 6}$ are between those of the single reinforcements and of the matrix PA6. According to previous studies in polymer blends [36], interchange reactions between PA6 from the matrix and from the reinforcements can be supposed leading to the formation of block copolymers. This would result in chemical bonds across the matrix-fiber interface enhancing the adhesion.

\subsection{X-ray diffraction studies}

To better understand the differences and similarities between the PA6 matrix and reinforcement in $\mathrm{KSPCS}_{P A 6}$ and their precursors, X-ray diffraction studies were performed. The linear diffraction patterns of representative samples were collected and deconvoluted by peak fitting. Eq. (3) was implemented to calculate the total crystallinity index and the specific content of $\alpha$ - and $\gamma$-PA6 polymorphs. According to previous findings [36], a monoclinic unit cell lattice was assumed for the $\alpha$-PA6 form characterized by two peaks corresponding to $\alpha\left[\begin{array}{ll}2 & 0\end{array}\right]$ and $\alpha[002 / 202]$ crystalline planes with $2 \theta$ being centered in the studied samples at ca. $20^{\circ}$ and $23^{\circ}$, respectively. For the $\gamma$-crystalline form, non-hexagonal unit cell was supposed for all samples, as suggested by Samon et al. [37]. Therefore, fits with two Gaussian peaks corresponding to $\gamma\left[\begin{array}{llll}0 & 0 & 1\end{array}\right]$ and $\gamma\left[\begin{array}{lll}2 & 0 & 0\end{array}\right]$ crystalline planes were performed with $2 \theta$ being between 21 and $22^{\circ}$. The diffuse scattering of the amorphous PA6 component was presented by two wide Gaussian peaks (halos). This procedure led to very good fits with fitting coefficients $\mathrm{r}^{2}$ $\approx 0.99$. Representative X-ray patterns and their deconvolutions are shown in Fig. 6.

Let's first consider the XRD patterns of the matrix precursors in $K S P C S_{P A 6}$, the $M{ }_{S_{P A 6}}$ and PN (Fig. 6a and b). These patterns belong to non-oriented samples, in which the $\alpha$-PA6 reflections are narrower than those of the $\gamma$-polymorph. In the PN sample obtained after melting/ recrystallization of $M P_{P A 6}$ the $\alpha[200]$ reflection is weaker than the

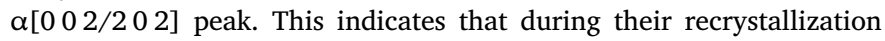
from the melt, the $\alpha$-crystallites in this sample display an increased growth along the plane determined by the H-bonds. In the patterns of the Rib textile reinforcements before and after annealing (Fig. $6 \mathrm{c}$ and d), both PA6 polymorphs are fitted with wider and symmetric (in the case of $\alpha$-PA6) crystalline peaks, which is typical for oriented PA6. In addition, comparing visually the widths of the $\alpha$-PA6 peaks in Fig. 6 allows the conclusion that the anionic PA6 of the $M P S_{P A 6}$ and the plates obtained thereof (PN) comprises smaller but more perfect crystallites than the hydrolytic PA6 of the knitted textile reinforcements.

The fitted XRD patterns of the $K_{S P C S_{P A 6}}$ in Fig. 7 allowed the clear

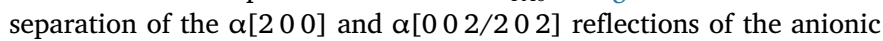
matrix PA6 and the hydrolytic PA6 of the textile structures. For the peaks of the two $\gamma$-polymorphs, however, such separation was 

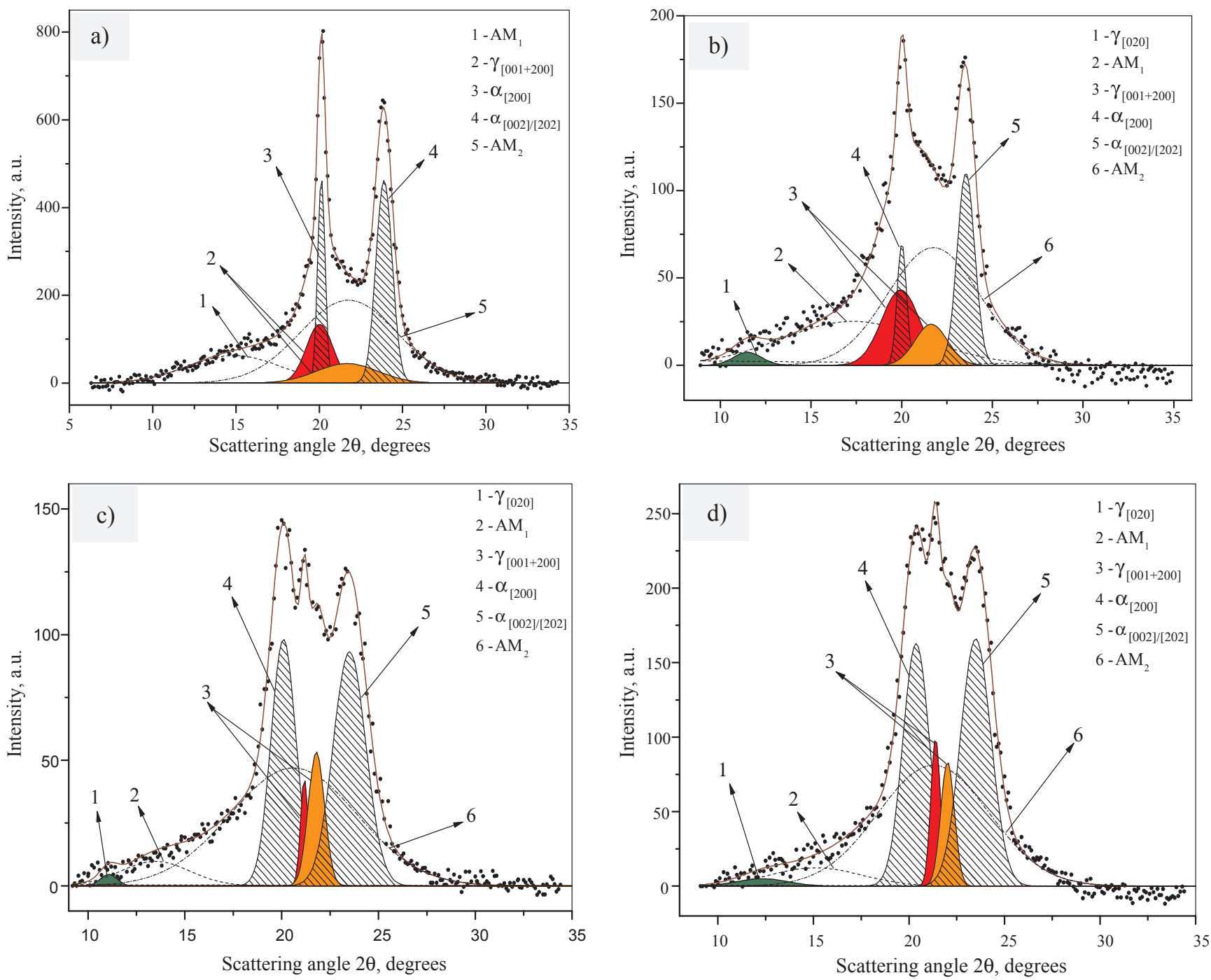

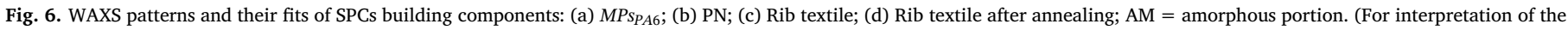
references to colour in this figure legend, the reader is referred to the web version of this article.)

impossible. In all $K S P C s_{P A 6}$ the $\alpha$-PA6 matrix peaks are wider than those of the textile reinforcements. This is logical since the anionic PA6 melted and recrystallized during the $K S P C S_{P A 6}$ preparation thus forming less perfect and non-oriented matrix crystallites, while the PA6 from the knitted textile filaments did not melt, remaining oriented. Notably, in the PM-J-15 and PM-R-15 composites (Fig. 7b and c) the two $\alpha$-reflections of the textile reinforcements are asymmetric with the $\alpha\left[\begin{array}{ll}0 & 02 /\end{array}\right.$ 202 ] peak becoming stronger. Since no melting of the reinforcing monofilament occurred, as shown by the microscopy study above, it can be supposed that the melting and the recrystallization of the matrix material during the laminate consolidation has led to an impeded growth of the $\alpha$-crystallites along the direction of the van der Waals forces between the PA6 molecules forming the crystalline plane.

More conclusions about the crystalline structure and the crystallinity index $X_{c}^{X R D}$ of the materials under investigation can be made based on the data in Table 4. The d-spacings for all $\alpha$ - and $\gamma$-PA6 reflections were also calculated and tabulated. Comparing the $M P_{S_{P A 6}}$ and PN samples indicates that transforming the anionic microparticles into matrix of the $M P_{S_{P A 6}}$ by melting at $215^{\circ} \mathrm{C}$ results in a $\alpha$ - to $\gamma$-polymorph transition, which decreased the $X_{c}^{X R D}$ (from $42 \%$ to $35 \%$ ) and the $\alpha / \gamma$ ratio. The untreated knitted textile reinforcements had $X_{c}^{X R D}$ values of ca. $40 \%$, i.e., similar to that of $M P S_{P A 6}$ and lower than the PN. The untreated Rib structure, however, is significantly richer in $\alpha$-PA6 than the former two anionic samples with its $\alpha / \gamma$ ratio being above 3 .
Stretching the knitted textile reinforcements to $30 \%$ accompanied by annealing at $170{ }^{\circ} \mathrm{C}$ for $90 \mathrm{~min}$ results in a massive growth of the crystallinity index of about $10 \%$, reaching values of $53-54 \%$ that are very high for PA6. At the same time, the $\alpha / \gamma$ ratio is maintained between 3 and 4.

Table 4 shows also that the $\gamma\left[\begin{array}{ll}0 & 2\end{array} 0\right]$ reflection of the annealed Jersey (J-A sample) is better revealed as compared to that in the R-A, meaning that the different textile architecture may result in different crystallization behavior during the stress-relaxation of the knitted reinforcements and the compression molding procedure. A general common feature of the $K_{S P C S_{P A 6}}$ is that the $\alpha$-PA6 content in the matrix is always lower than that in the embedded textile structure. The difference between the two values seems to be dependent on the type of the knitting pattern and the alignment of the textile ply in one or more direction. The $X_{c}^{X R D}$ values of the studied $K S P C S_{P A 6}$ vary between $42 \%$ (PM-J-15) and $51 \%$ (PU-J-20) and the $\alpha / \gamma$ ratio - between 1.2 for PM-J-15 and 2.7 for PU-J-25. Such differences can be considered significant. It seems that the different textile ply pattern and alignment can really affect the crystallization process which is expected to result in different mechanical behavior. Table 4 allows also the conclusion that the long spacing values $d_{h k l}$ that determine the unit cell edges of the $K_{S P C S_{P A 6}}$ matrix and reinforcement differ only slightly. The difference is in the margin of the experimental error. 

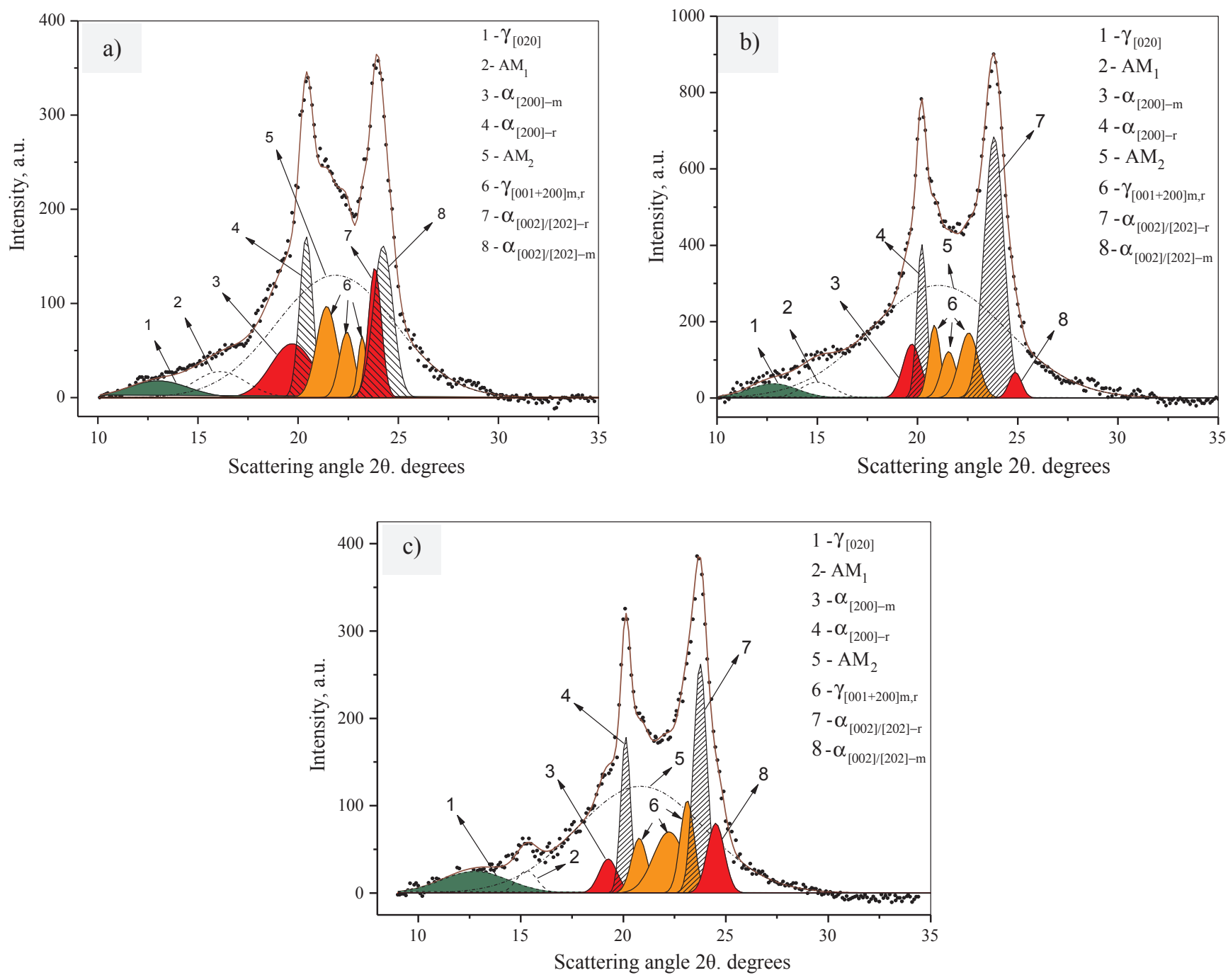

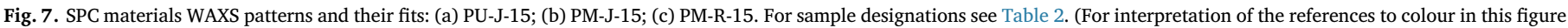
legend, the reader is referred to the web version of this article.)

\subsection{Tensile strength experiments}

Since the mechanical properties of a laminate composite strongly depend on the tensile strength and stiffness of the reinforcements, single textile plies of both Jersey and Rib type were tested in tension, before and after the annealing treatment, applied at different angles in relation to the wale direction (Fig. 8). As seen from Fig. 8a (R-A, J-A curves), stretching to $30 \%$ accompanied by heating at $170{ }^{\circ} \mathrm{C}$ for $90 \mathrm{~min}$ resulted in the appearance of a clear elastic region in the stress-strain curves between 0 and $5 \%$ of relative strain that was absent in the $\mathrm{R}$ and $\mathrm{J}$ samples. Moreover, in both annealed samples the second elastic region observed above $\varepsilon=40 \%$ has a higher slope than the non-treated textiles, which indicates a higher $E$-modulus. This behavior can be related to the higher total crystallinity index of the J-A and R-A samples that was observed by either DSC or XRD and showed a 13\% difference in the Rib reinforcements when compared to the non-treated samples. Table 4 shows that it is the $\alpha$-PA6 content that increases during the stretching/annealing whereas the $\gamma$-PA6 remains relatively constant. These results are consistent with previous studies on the structuremechanical properties relationship in oriented PA6 annealed at $170-200{ }^{\circ} \mathrm{C}$ [38]. Therefore, the big increase in $E$ and $\sigma_{\max }$ values upon annealing were proved to be related to a $\gamma$-to- $\alpha$ form transition.

Straining of annealed knitted structures at different angles relative to the wale direction (Fig. 8b) resulted in tensile stiffness $(E)$ values for the Jersey pattern at $0^{\circ}$ and $90^{\circ}$ of $27-30 \mathrm{MPa}$, whereas at $45^{\circ}$ direction only 9.0 MPa was registered. With the Rib pattern, the stiffness was higher along the wale direction (i.e., $0^{\circ}, E=15.0 \mathrm{MPa}$ ), while in the other two directions, twice as lower results were obtained. Apparently, these effects are related to the different architecture of the $\mathrm{R}$ and $\mathrm{J}$ textiles that deform in a different way when subjected to bi-dimensional strain during the annealing procedure. Table 5 demonstrates tensile properties of all stretched-annealed knitted textile reinforcements and the PA6 filament. The values presented in Table 5 are in accordance with regular texturized commercial PA6 filaments.

Fig. 9 represents the stress-strain curves of $K_{S P C S_{P A 6}}$ materials with uni- or multidirectional laminate sets tested in two perpendicular directions. The neat anionic matrix PN is presented to enable comparison. Table 6 displays the data on the Young's modulus E, maximum tensile strength $\sigma_{\max }$ and the strain at break $\varepsilon_{\mathrm{br}}$ deduced from the stress-strain curves. Changing the strain direction to $90^{\circ}$ in relation to the wales direction resulted in the stress-strain curves in Fig. 9b. Their shape remained unchanged but the $\mathrm{E}$ and $\sigma_{\max }$ values dropped becoming close or slightly below those of the PN reference (Table 6). Fig. 9c presents a comparison between the stress-strain curves of unidirectional (PU series) and multidirectional (PM series) laminates with three textile plies $(\mathrm{Vf}=15 \%)$. The PM composites displayed higher $\varepsilon_{b r}$ values when compared to the PU homologues, best expressed in the KSPCS $S_{P A 6}$ with Jersey reinforcements. On the other hand, the highest $\sigma_{\max }$ and E-values 
Table 4

Data from the deconvolution of the XRD patterns of SPCs, textile structures and anionic PA6 precursors.

\begin{tabular}{|c|c|c|c|c|c|c|c|c|c|}
\hline Sample & $\alpha \%$ & $\gamma \%$ & $X_{c}^{X R D}, \%$ & $\frac{\alpha}{\gamma}$ & $d_{\alpha(200)} \AA$ & $d_{\alpha(002 / 202)} \AA$ & $d_{\gamma(020)} \AA$ & $d_{\gamma(001)} \AA$ & $d_{\gamma(200)} \AA$ \\
\hline$M P_{P A 6}$ & 26.5 & 15.2 & 41.7 & 1.74 & 4.29 & 3.62 & - & 4.31 & 3.99 \\
\hline PN & 17.4 & 17.5 & 34.9 & 1.00 & 4.32 & 3.68 & 7.48 & 4.33 & 4.00 \\
\hline$J-A$ & 41.0 & 11.8 & 52.8 & 3.47 & 4.35 & 3.74 & 6.13 & 4.10 & 3.96 \\
\hline R-A & 42.9 & 10.7 & 53.6 & 4.00 & 4.24 & 3.68 & 6.97 & 4.04 & 3.93 \\
\hline $\mathrm{R}$ & 31.0 & 9.5 & 40.5 & 3.26 & 4.30 & 3.68 & 7.78 & 4.08 & 3.97 \\
\hline PU-J-15 & $\begin{array}{l}13.0^{\mathrm{R}} \\
18.0^{\mathrm{M}} \\
31.0^{\mathrm{T}}\end{array}$ & 14.9 & 45.9 & 2.08 & $\begin{array}{l}4.38^{\mathrm{R}} \\
4.23^{\mathrm{M}}\end{array}$ & $\begin{array}{l}3.57^{\mathrm{R}} \\
3.63^{\mathrm{M}}\end{array}$ & 6.57 & 4.03 & $\begin{array}{l}3.86^{\mathrm{R}} \\
3.73^{\mathrm{M}}\end{array}$ \\
\hline PU-J-20 & $\begin{array}{l}10.9^{\mathrm{R}} \\
20.9^{\mathrm{M}} \\
\mathbf{3 1 . 8 ^ { \mathrm { T } }}\end{array}$ & 19.3 & 51.1 & 1.65 & $\begin{array}{l}4.48^{\mathrm{R}} \\
4.27^{\mathrm{M}}\end{array}$ & $\begin{array}{l}3.58^{\mathrm{R}} \\
3.65^{\mathrm{M}}\end{array}$ & 6.45 & 4.07 & $\begin{array}{l}3.91^{\mathrm{R}} \\
3.77^{\mathrm{M}}\end{array}$ \\
\hline PU-J-25 & $\begin{array}{l}15.4^{\mathrm{R}} \\
18.3^{\mathrm{M}} \\
33.7^{\mathrm{T}}\end{array}$ & 12.5 & 46.2 & 2.69 & $\begin{array}{l}4.42^{\mathrm{R}} \\
4.25^{\mathrm{M}}\end{array}$ & $\begin{array}{l}3.61^{\mathrm{R}} \\
3.65^{\mathrm{M}}\end{array}$ & 6.78 & 4.07 & $\begin{array}{l}3.92^{\mathrm{R}} \\
3.80^{\mathrm{M}}\end{array}$ \\
\hline PU-R-15 & $\begin{array}{l}8.7^{\mathrm{R}} \\
19.7^{\mathrm{M}} \\
28.4^{\mathrm{T}}\end{array}$ & 15.3 & 43.7 & 1.86 & $\begin{array}{l}4.41^{\mathrm{R}} \\
4.25^{\mathrm{M}}\end{array}$ & $\begin{array}{l}3.51^{\mathrm{R}} \\
3.63^{\mathrm{M}}\end{array}$ & 6.06 & 4.04 & $\begin{array}{l}3.94^{\mathrm{R}} \\
3.75^{\mathrm{M}}\end{array}$ \\
\hline PM-J-15 & $\begin{array}{l}4.7^{\mathrm{R}} \\
24.2^{\mathrm{M}} \\
\mathbf{2 8 . 9 ^ { \mathrm { T } }}\end{array}$ & 12.7 & 41.6 & 2.28 & $\begin{array}{l}4.37^{\mathrm{R}} \\
4.27^{\mathrm{M}}\end{array}$ & $\begin{array}{l}3.48^{\mathrm{R}} \\
3.63^{\mathrm{M}}\end{array}$ & 6.71 & 4.15 & $\begin{array}{l}4.01^{\mathrm{R}} \\
3.84^{\mathrm{M}}\end{array}$ \\
\hline PM-R-15 & $\begin{array}{l}7.0^{\mathrm{R}} \\
17.7^{\mathrm{M}} \\
24.7^{\mathrm{T}}\end{array}$ & 21.1 & 45.8 & 1.17 & $\begin{array}{l}4.48^{\mathrm{R}} \\
4.26^{\mathrm{M}}\end{array}$ & $\begin{array}{l}3.53^{\mathrm{R}} \\
3.64^{\mathrm{M}}\end{array}$ & 6.72 & 4.16 & $\begin{array}{l}3.89^{\mathrm{R}} \\
3.74^{\mathrm{M}}\end{array}$ \\
\hline
\end{tabular}

R: Reinforcement.

M: Matrix.

T: Total.
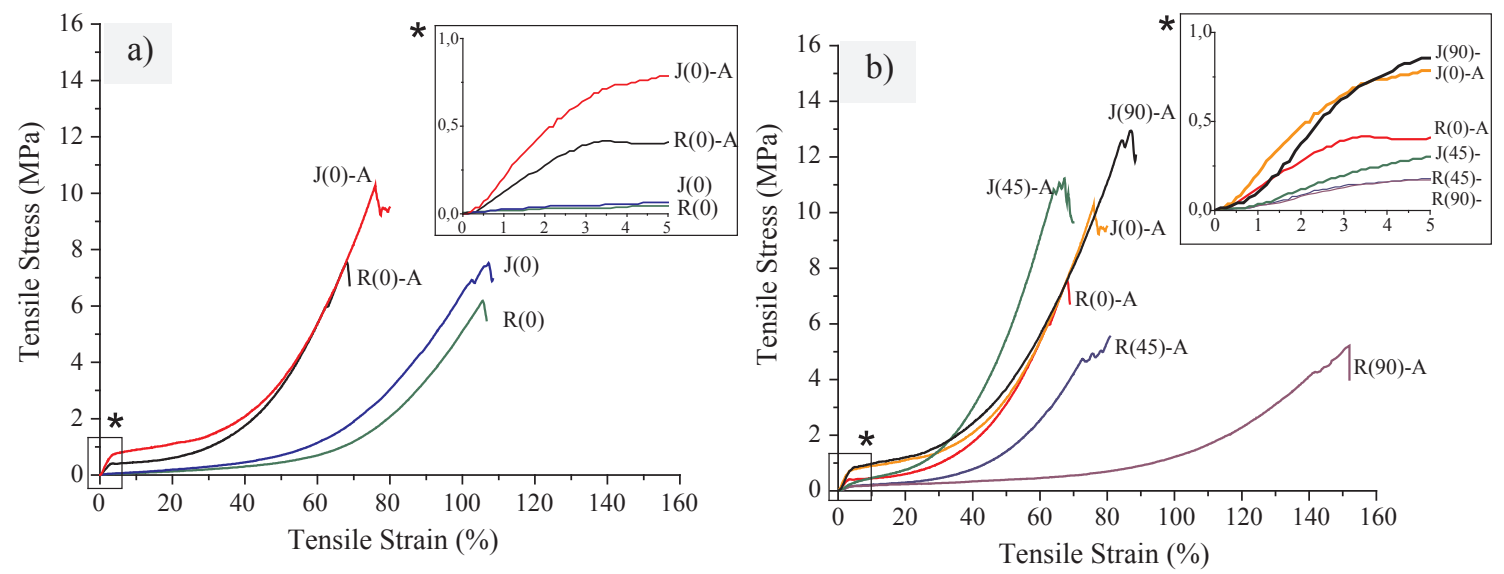

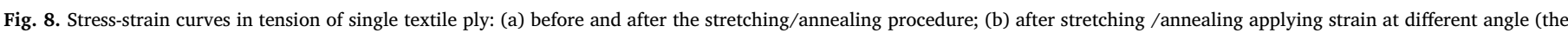

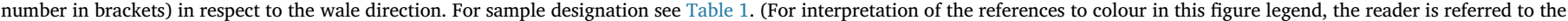
web version of this article.)

Table 5

Tensile properties of stretched-annealed knitted reinforcement.

\begin{tabular}{llll}
\hline Samples & $\begin{array}{l}\text { Tensile Stiffness } \\
(\mathrm{MPa})\end{array}$ & $\begin{array}{l}\text { Tensile Strength } \\
(\mathrm{MPa})\end{array}$ & $\begin{array}{l}\text { Tensile Strain at break } \\
(\%)\end{array}$ \\
\hline Filament & $9.2 \pm 0.15$ & $3.5 \pm 0.1$ & $45.0 \pm 0.1$ \\
R(0)-A & $15.1 \pm 0.9$ & $6.2 \pm 0.2$ & $64.4 \pm 1.6$ \\
R(45)-A & $6.3 \pm 0.3$ & $4.5 \pm 0.3$ & $71.5 \pm 2.0$ \\
R(90)-A & $5.4 \pm 0.2$ & $4.4 \pm 0.1$ & $145.5 \pm 1.1$ \\
J(0)-A & $26.7 \pm 1.5$ & $8.6 \pm 0.2$ & $67.8 \pm 0.9$ \\
J(45)-A & $9.1 \pm 0.4$ & $10.1 \pm 0.6$ & $62.6 \pm 1.2$ \\
J(90)-A & $29.7 \pm 1.2$ & $10.6 \pm 0.5$ & $78.8 \pm 1.7$ \\
\hline
\end{tabular}

were obtained in the composites with either uni- or multidirectional ply sets containing Rib textile reinforcements (Fig. 9c, curves 2,3; Table 6).

As seen from the averaged mechanical data tabulated in Table 6, the fiber volume fraction and stacking order slightly influences the tensile properties of the $K_{S P C} C_{P A 6}$ although reinforcement architecture brought significant changes. Rib structure promoted better tensile properties of $K S P C_{P A 6}$; hence, the best tensile stiffness (ca. 1.9 GPa) and strength (ca. $68 \mathrm{MPa}$ ) achieved for Rib reinforced $K S P C_{P A 6}$ respect to the wale (0) direction. The multidirectional stacking order outstandingly increased the ductility of $K S P C_{P A 6}$ although the changes were considerable for Jersey reinforced $K S P C_{P A 6}$. Unlike unidirectional reinforced $K S P C_{P A 6}$, laminating the knitted reinforcement with different stacking order caused significant discrepancy between the maximum tensile stress and stress at failure. This difference represents the necking behavior of the $K_{S P C S_{P A 6}}$ in which large amounts of strain are localized disproportionately in a small region of the material.

Unlike the single textile structures, the mechanical properties of the $K S P C S_{P A 6}$ materials cannot be related solely to their crystalline structure as determined by DSC of XRD. The textile ply arrangement and knitted architecture seem to have a significant influence on the $K_{S P C S_{P A 6}}$ mechanical behavior. To better assess and understand this relation a structural analysis and geometrical modelling studies were carried out. 

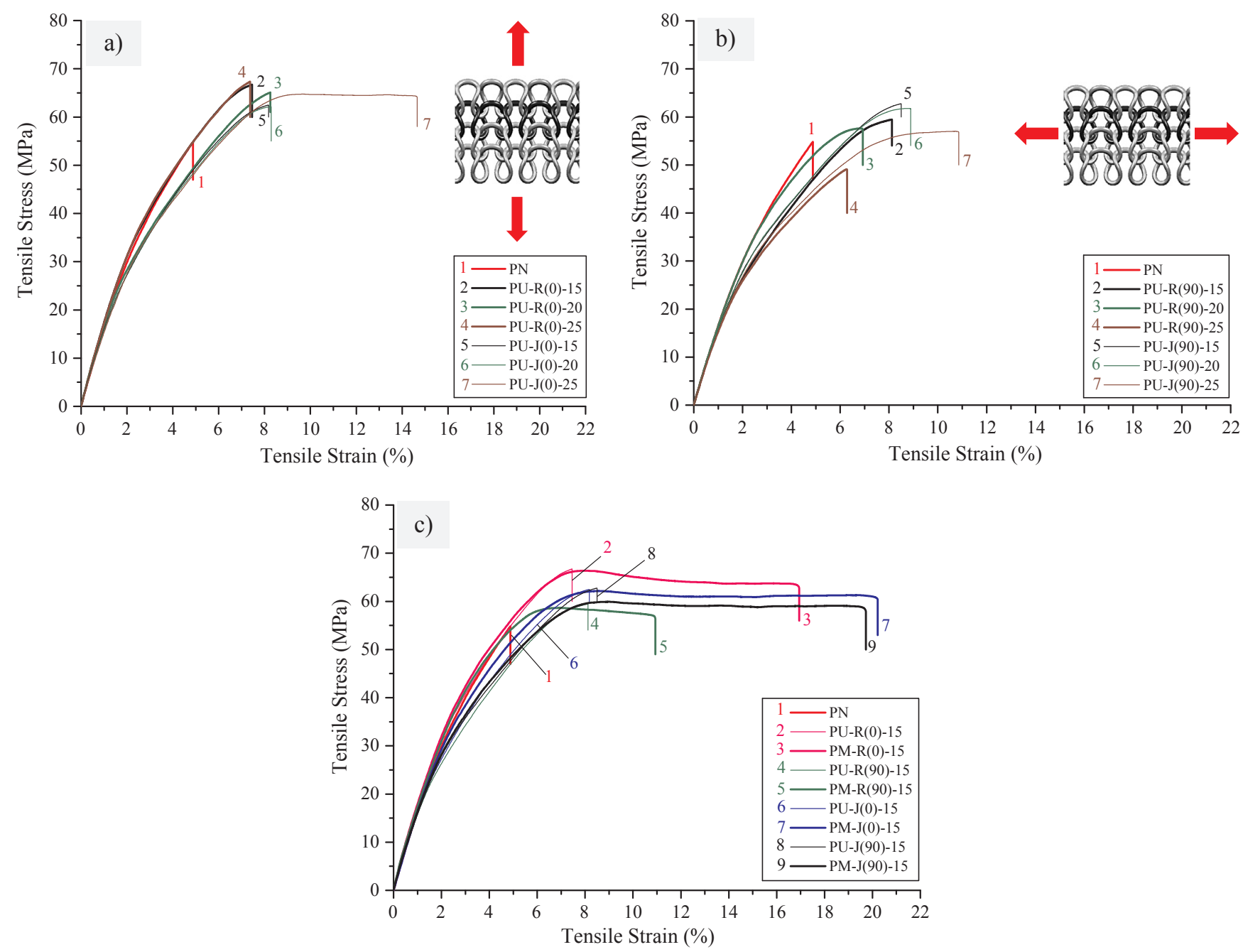

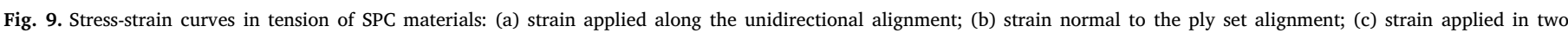

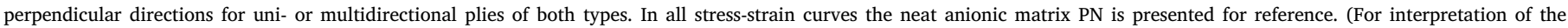
references to colour in this figure legend, the reader is referred to the web version of this article.)

\subsection{Tensile failure analysis}

A structural analysis of the knitted reinforcements was performed to correlate the tensile properties of $K_{S P C S_{P A 6}}$ with the composite fracture surface configuration. Fig. 10 presents SEM images of tensile failure cross- sections of uni-and multidirectional annealed Rib reinforced KSPCS $_{P A 6}$ with $15 \mathrm{wt} \%$ fiber contents. The fracture surface in Fig. 10a-c demonstrates the advent of the crossover points which architecturally defined by the junction of the sinker loop and loop head (Fig. 10d). In addition, knitted reinforcements were installed with slight longitudinal differences in which the loops of each plies could not be perfectly aligned upon each other. Therefore, it can be deduced that differences on plies longitudinal alignment did not cause the distinct fracture surface configuration. Meanwhile, despite the plie alignments and orientations, the fracture surface cross section of $K S P C S_{P A 6}$ ascertained that the highly stressed cross over points in knitted structure were responsible of tensile failure.

Meanwhile, measuring the quantity of crossover points in annealed knitted reinforcement structures enhanced to understand better feeble tensile properties of Jersey reinforced $K S P C_{P A G}$. Fig. $10 \mathrm{a}$ and b displays the simulated annealed Rib and Jersey reinforcements, respectively. Ten digitalized microscopic images were captured from the technical face surface of each knitted reinforcement and used to draw, with the AutoCAD software, the base points of the kernel geometry. Afterward the determined kernel geometry imported to the SolidWorks software to sweep the yarn profile along it.

To simplify the simulation procedure, three major hypotheses were considered: (i) The filament cross section is elliptical; (ii) The sweeping of elliptical cross section through the kernel geometry was constant and (iii) At cross over points, no dimensional deformation occurred. At the end, a virtual clash test was run to evaluate the contact situation on each crossover point. To assess the contribution of loop configuration to the tensile failure of composites a geometrical study of the loop was carried out. Fig. 11a-d shows the breaking up of each loop into straight sections within six-degree intervals, which were projected in the wale (0) and course (90) directions to obtain the average loop fraction contribution- Loop Partition fraction (LPF\%) - in the respective direction. This helped finding the principal orientation of filaments in the knitted structure. Moreover, measuring the length of each loop partition (Loop Partition Length -LPL) and the loop length from the simulated loop cell can support further failure analysis of $K S P C S_{P A 6}$.

The constructional parameters of the annealed knitted fabrics were also considered to evaluate the number of cross-over points. Fig. 12a plots the number of wales per centimeter (WPC), courses per centimeter $(\mathrm{CPC})$ and stitch density (WPC $\times \mathrm{CPC}$ ) for the annealed knitted reinforcements. The Jersey structure contains higher stitch density than Rib, hence, the number of crossover points increased for Jersey reinforcements. Fig. 12b shows the LPL magnitude of each loop for both knitted structures. As it can be observed, the sinker loop length of the Jersey structure is significantly lower than that of the Rib. These two 
Table 6

Data about the secant Young's modulus E, maximum tensile strength $\sigma_{\max }$ and strain at break $\varepsilon_{\text {br }}$ deduced from the mechanical tests in tension.

\begin{tabular}{llllll}
\hline Sample designation & E, (GPa) & IF, ${ }^{\mathrm{b}}$ & $\sigma_{\max },(\mathrm{MPa})$ & $\mathrm{IF}, \%$ & $\varepsilon_{b r}, \%$ \\
\hline PN & $1.73 \pm 0.02$ & - & $57,3 \pm 0,9$ & - & $5.2 \pm 0.1$ \\
Durethan B30S & & & & \\
a & $1.03 \pm 0.04$ & -40 & $51.2 \pm 2.0$ & -11 & $37 \pm 6$ \\
PU-R (0)-15 & $1.93 \pm 0.03$ & 11 & $65,9 \pm 0.7$ & 15 & $9.2 \pm 0.5$ \\
PU-R (0)-20 & $1.68 \pm 0.02$ & -3 & $64,2 \pm 0.6$ & 12 & $8.5 \pm 0.4$ \\
PU-R (0)-25 & $1.87 \pm 0.03$ & 2 & $67.4 \pm 0.4$ & 18 & $10.3 \pm 0.1$ \\
PU-R (90)-15 & $1.62 \pm 0.01$ & -7 & $58,7 \pm 0,6$ & 2 & $8.4 \pm 0.6$ \\
PU-R (90)-20 & $1.72 \pm 0.04$ & 0 & $55.3 \pm 0.6$ & -3 & $7.1 \pm 0.1$ \\
PU-R (90)-25 & $1.63 \pm 0.05$ & -6 & $43.0 \pm 0.7$ & -25 & $6.4 \pm 0.2$ \\
& & & & & \\
PU-J (0)-15 & $1.66 \pm 0.05$ & -4 & $62.1 \pm 0.3$ & 8 & $8.9 \pm 0.4$ \\
PU-J (0)-20 & $1.61 \pm 0.03$ & -7 & $62.3 \pm 0.5$ & 9 & $9.7 \pm 0.6$ \\
PU-J (0)-25 & $1.65 \pm 0.03$ & -5 & $65.3 \pm 0.8$ & 14 & $19.8 \pm 0.3$ \\
PU-J (90)-15 & $1.69 \pm 0.01$ & -2 & $63.1 \pm 0.3$ & 10 & $13.6 \pm 0.5$ \\
PU-J (90)-20 & $1.58 \pm 0.03$ & -9 & $61.3 \pm 0.6$ & 7 & $13.8 \pm 0.7$ \\
PU-J (90)-25 & $1.53 \pm 0.01$ & -12 & $61.9 \pm 0.6$ & 8 & $11.8 \pm 0.7$ \\
PM-R (0)-15 & $1.78 \pm 0.03$ & 3 & $63.6 \pm 0.4$ & 11 & $16.9 \pm 0.1$ \\
PM-R (90)-15 & $1.76 \pm 0.02$ & 2 & $59.3 \pm 0.5$ & 3 & $11.0 \pm 0.2$ \\
PM-J (0)-15 & $1.69 \pm 0.02$ & -2 & $62.2 \pm 0.2$ & 9 & $19.6 \pm 0.8$ \\
PM-J (90)-15 & $1.67 \pm 0.02$ & -4 & $59.8 \pm 0.6$ & 4 & $20.0 \pm 0.7$ \\
& & & & &
\end{tabular}

${ }^{\text {a }}$ Commercial neat hydrolytic PA6 of BASF, Germany, compression molded granulate [38].

${ }^{\mathrm{b}} I F=\frac{P_{i}^{S P C}-P_{i}^{\text {matrix }}}{P_{i}^{\text {matrix }}}$ where $P_{i}^{S P C}$ and $P_{i}^{\text {matrix }}$ are the respective parameters of the

composite and matrix materials.

characteristics - higher stitch density together with lower sinker loop length - can lead to higher stress concentration at cross-over points,

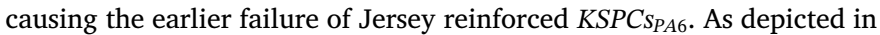
Fig. 12c, the major contribution of each loop cell is in the wale direction, which can explain the higher tensile properties of unidirectional annealed Rib reinforced $K_{S P C S_{P A 6}}$ in that direction (see Fig. 9). Fig. 12c
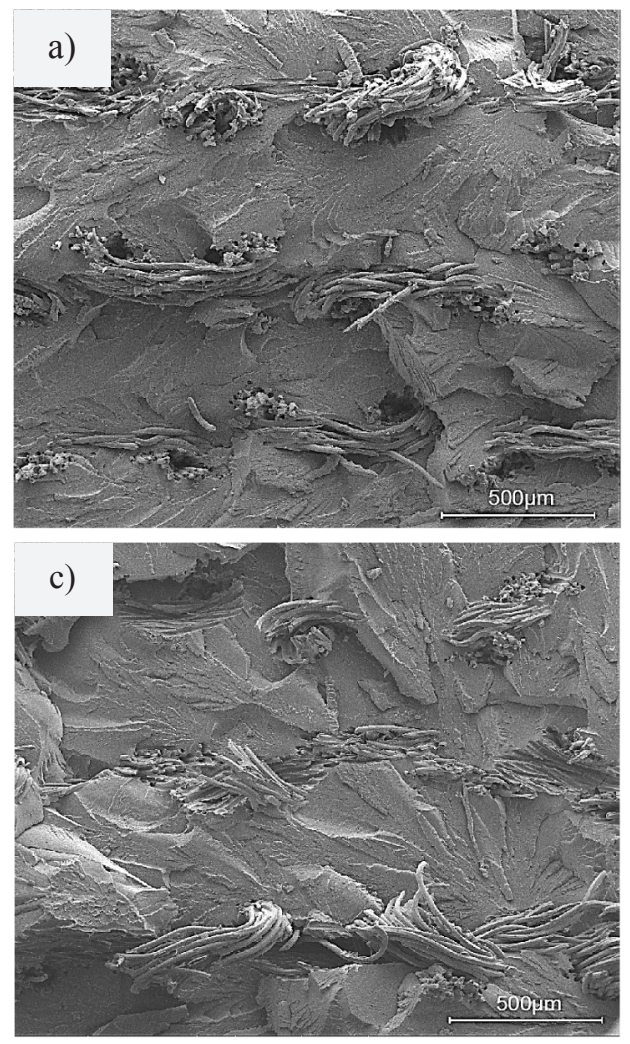

also demonstrates identical contribution o loop partitions in the wale and course directions for diagonal embedded knitted reinforcements. Therefore, the higher ductility and necking behavior of multidirectional $K S P C_{P A 6}$ can be explained by the identical LPF value obtained in the diagonal embedded knitted reinforcements, which resulted in equal stress distribution in the cross-section. This caused the delay of tensile breakage of the middle plie (diagonally embedded) while the top and bottom plies failed. The SEM images of surface fracture in multidirectional $K S P C_{P A 6}$ prove this fact, by showing a more even fracture surface of the composite (see Fig. 10c).

\section{Conclusions}

Knitted reinforced single polymer composites based on polyamide 6 $\left(K S P C S_{P A 6}\right)$ were successfully prepared by combination of powdercoating and compression molding techniques. Annealing treatment of the Rib and Jersey knitted textile reinforcements showed impressive improvement of the mechanical properties. The influence of reinforcement architecture, fiber volume fraction varied between 15 and $25 \%$, reinforcement orientation (wale and course directions) and its directional stacking order $(0 / 45 / 0$ and $90 / 45 / 90)$ on the tensile properties of $K S P C S_{P A 6}$ was evaluated. Polarized light microscopy and SEM studies evidenced a homogeneous distribution of PA6 monofilaments in the knitted reinforcements, without damage caused during the consolidation of the laminates by hot pressing. At the interface region, presence of a transcrystalline layer (TCL) was supposed based on thickness discrepancies between the annealed monofilaments and the ones embedded in the ${ } S P C S_{P A 6}$. The results showed that the Rib reinforced $K S P C S_{P A 6}$ with fiber content $15 \%$ and all plies aligned along the wale direction, displayed the best improvement of tensile stiffness and strength as compared to anionic and conventional hydrolytic PA6 matrix. The fracture behavior of the KSPCS $S_{P A 6}$ was found to depend on the crystalline morphology of composite components and on the structural
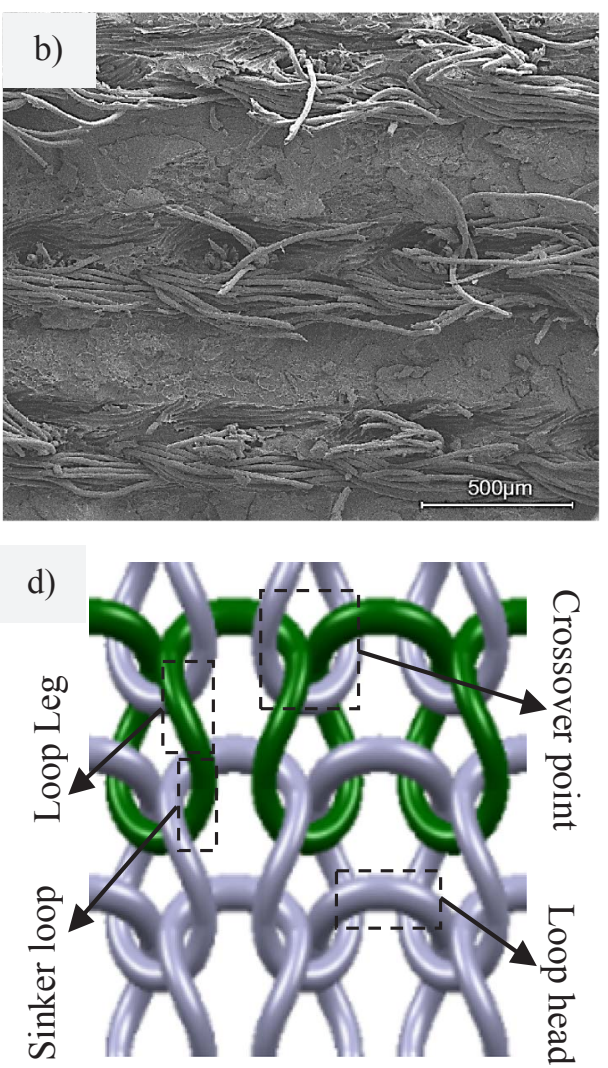

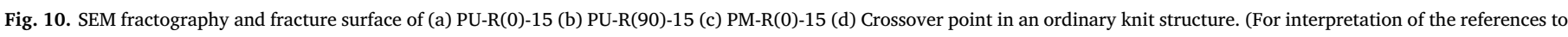
colour in this figure legend, the reader is referred to the web version of this article.) 

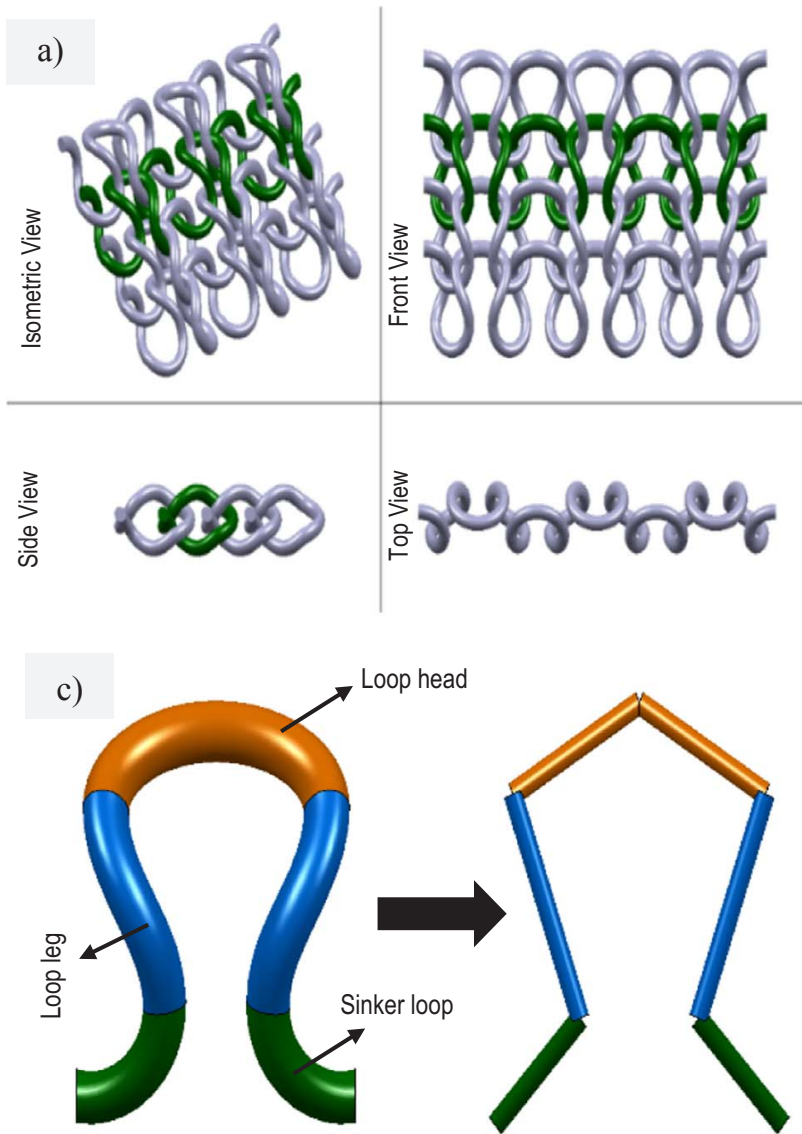
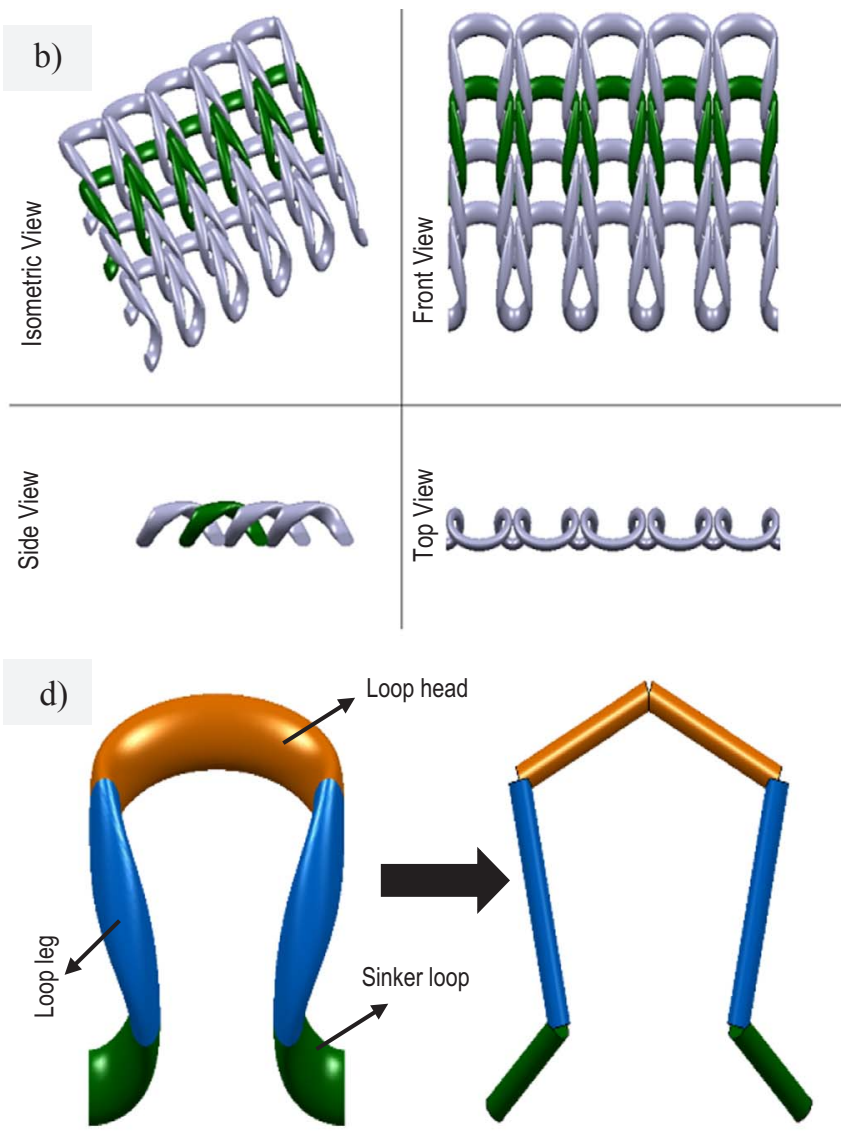

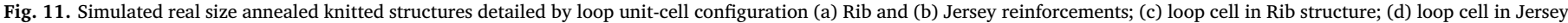
structure. (For interpretation of the references to colour in this figure legend, the reader is referred to the web version of this article.)
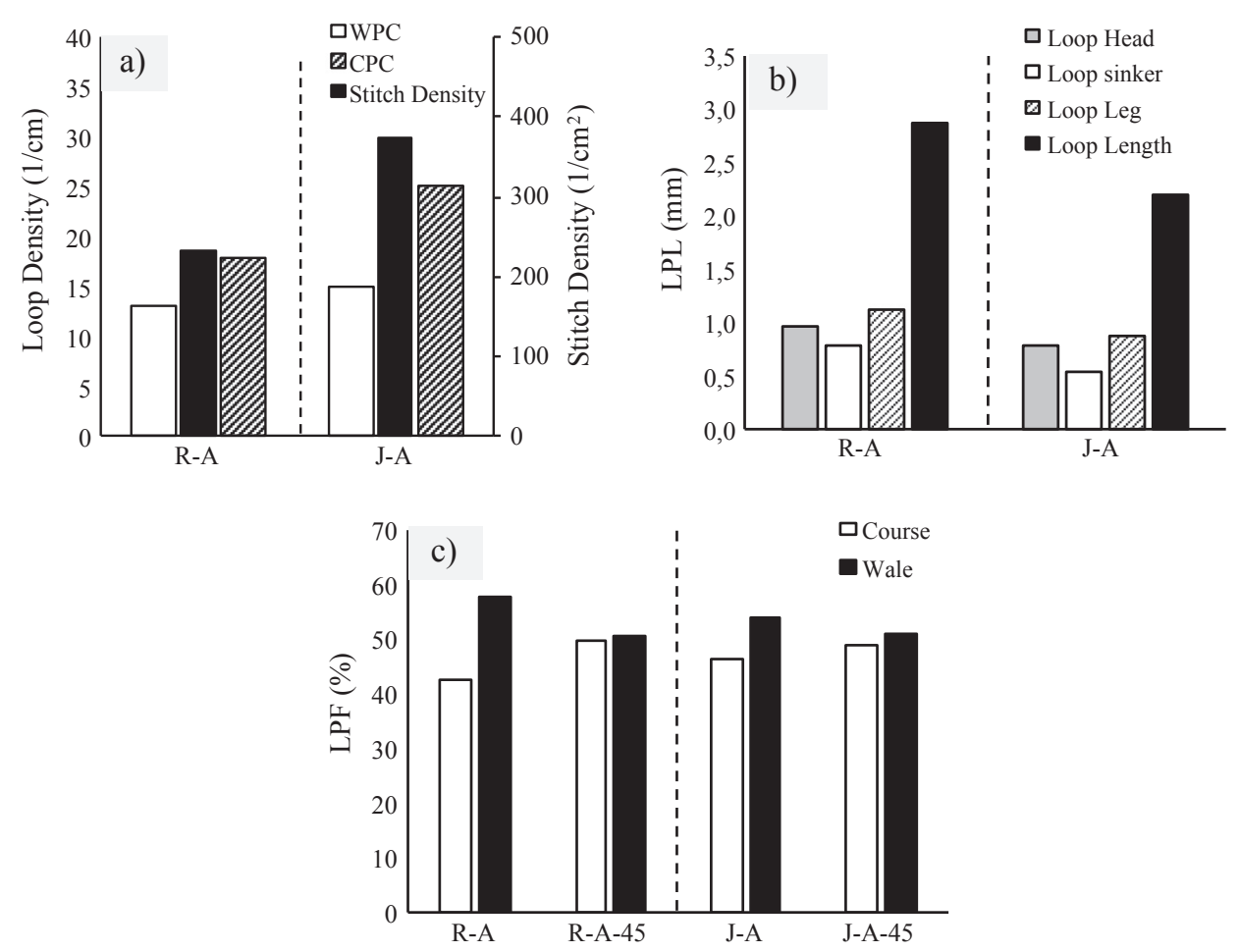

Fig. 12. Comparative study on (a) knitted reinforcements loop density; (b) LPL (mm); (c) LPF (\%). 
deformation of the knitted reinforcements, in which crossover points were the main factors responsible for tensile failure. Further improvement of the SPCs mechanical behavior will require alternative reinforcement's architecture, optimization of their surface and studying the interlaminar shear strength of the SPCs as a function of ply amount and alignment.

\section{Acknowledgements}

All authors gratefully acknowledge the support of the project TSSiPRO-NORTE-01-0145-FEDER-000015 funded by the regional operational program NORTE 2020, under the PORTUGAL 2020 Partnership Agreement, through the European Regional Development Fund. This work was partially financed by FEDER funds through the Competitiy Factors Operational Program - COMPETE and by national funds through FCT - Foundation for Science and Technology within the project POCI-01-0145-FEDER-007136. SDT thanks FCT for his PhD Grant SFRH/BD/94759/2013. NVD thanks for the financial support of FCT through the strategic projects LA25/2013-2014 and UID/CTM/ $50025 / 2013$. Finally, ZZD is thankful to FCT for the SFRH/BSAB/ $130271 / 2017$ personal research grant.

\section{References}

[1] Karger-Kocsis J, Bárány T. Single-polymer composites (SPCs): status and future trends. Compos Sci Technol 2014;92:77-94.

[2] Kmetty Á, Bárány T, Karger-Kocsis J. Self-reinforced polymeric materials: a review. Prog Polym Sci 2010;35:1288-310.

[3] Fakirov S. Nano- and microfibrillar single-polymer composites: a review. Macromol Mater Eng 2013;298:9-32. http://dx.doi.org/10.1002/mame.201200226.

[4] Karger-Kocsis J, Mahmood H, Pegoretti A. Recent advances in fiber/matrix interphase engineering for polymer composites. Prog Mater Sci 2015;73:1-43.

[5] Khondker OA, Fukui T, Inoda M, Nakai A, Hamada H. Fabrication and mechanical properties of aramid/nylon plain knitted composites. Compos Part A Appl Sci Manuf 2004;35:1195-205.

[6] Yao D, Li R, Nagarajan P. Single-polymer composites based on slowly crystallizing polymers. Polym Eng Sci 2006;46:1223-30. http://dx.doi.org/10.1002/pen.20583.

[7] La Mantia FP, Curto D, Scaffaro R. Recycling of dry and wet polyamide 6. J Appl Polym Sci 2002;86:1899-903.

[8] Karger-Kocsis J, Zhang Z. Mechanical properties of polymers based on nanostructure and morphology. Struct Relationships Nanoparticle/Semicrystalline Thermoplast Compos Taylor Fr Abingt; 2005.

[9] Ward IM, Hine PJ. The science and technology of hot compaction. Polymer (Guildf) 2004;45:1413-27. http://dx.doi.org/10.1016/j.polymer.2003.11.050.

[10] Gong Y, Yang G. Single polymer composites by partially melting recycled polyamide 6 fibers: preparation and characterization. J Appl Polym Sci 2010;118:3357-63.

[11] Dubois P, Coulembier O, Raquez J-M. Handbook of ring-opening polymerization. John Wiley \& Sons; 2009.

[12] Gong Y, Liu A, Yang G. Polyamide single polymer composites prepared via in situ anionic polymerization of $\varepsilon$-caprolactam. Compos Part A Appl Sci Manuf 2010;41:1006-11.

[13] Dencheva N, Denchev Z, Pouzada AS, Sampaio AS, Rocha AM. Structure-properties relationship in single polymer composites based on polyamide 6 prepared by inmold anionic polymerization. J Mater Sci 2013;48:7260-73.
[14] Dencheva N, Sampaio AS, Oliveira FM, Pouzada AS, Brito AM, Denchev Z. Preparation and properties of polyamide-6-based thermoplastic laminate composites by a novel in-mold polymerization technique. J Appl Polym Sci 2014;131.

[15] Tohidi SD, Jeddi AAA, Nosrati H. Analyzing of the woven fabric geometry on the bending rigidity properties. Int J Text Sci 2013;2:73-80.

[16] Leong KH, Nguyen M, Herszberg I. The effects of deforming knitted glass fabrics on the basic composite mechanical properties. J Mater Sci 1999;34:2377-87.

[17] Khondker OA, Herszberg I, Leong KH. An investigation of the structure-property relationship of knitted composites. J Compos Mater 2001;35:489-508.

[18] Khondker OA, Leong KH, Herszberg I, Hamada H. Impact and compression-afterimpact performance of weft-knitted glass textile composites. Compos Part A Appl Sci Manuf 2005;36:638-48.

[19] Ramakrishna S, Hull D. Tensile behaviour of knitted carbon-fibre-fabric/epoxy laminates-Part I: Experimental. Compos Sci Technol 1994;50:237-47.

[20] Bini TB, Ramakrishna S, Huang ZM, Lim CT. Structure-tensile property relationship of knitted fabric composites. Polym Compos 2001:22:11-21.

[21] Brêda C, Dencheva N, Lanceros-Méndez S, Denchev Z. Preparation and properties of metal-containing polyamide hybrid composites via reactive microencapsulation. J Mater Sci 2016;51:10534-54.

[22] Dencheva N, Denchev Z, Lanceros-Méndez S, Ezquerra Sanz T. One-step in situ synthesis of polyamide microcapsules with inorganic payload and their transformation into responsive thermoplastic composite materials. Macromol Mater Eng 2016;301:119-24.

[23] Rusu G, Ueda K, Rusu E, Rusu M. Polyamides from lactams by centrifugal molding via anionic ring-opening polymerization. Polymer (Guildf) 2001;42:5669-78.

[24] Dencheva NV, Vale DM, Denchev ZZ. Dually reinforced all-polyamide laminate composites via microencapsulation strategy. Polym Eng Sci 2016.

[25] Oliveira F, Dencheva N, Martins P, Lanceros-Méndez S, Denchev Z. Reactive microencapsulation of carbon allotropes in polyamide shell-core structures and their transformation in hybrid composites with tailored electrical properties. eXPRESS Polym Lett 2016;10:160.

[26] Ramakrishna S. Characterization and modeling of the tensile properties of plain weft-knit fabric-reinforced composites. Compos Sci Technol 1997;57:1-22.

[27] Strong AB. Fundamentals of composites manufacturing: materials, methods and applications. Society of Manufacturing Engineers; 2008.

[28] Bureau MN, Denault J, Cole KC, Enright GD. The role of crystallinity and reinforcement in the mechanical behavior of polyamide-6/clay nanocomposites. Polym Eng Sci 2002;42:1897-906.

[29] Khanna YP, Kuhn WP. Measurement of crystalline index in nylons by DSC: complexities and recommendations. J Polym Sci Part B Polym Phys 1997;35:2219-31.

[30] Dencheva N, Nunes T, Oliveira MJ, Denchev Z. Microfibrillar composites based on polyamide/polyethylene blends. 1. Structure investigations in oriented and isotropic polyamide 6. Polymer (Guildf) 2005;46:887-901.

[31] Bhattacharyya D, Maitrot P, Fakirov S. Polyamide 6 single polymer composites. Express Polym Lett 2009;3:525-32.

[32] Sekiguchi H, Coutin B. Polymerizability and related problems in the anionic polymerization of lactams. J Polym Sci Polym Chem Ed 1973;11:1601-14.

[33] Murthy NS, Curran SA, Aharoni SM, Minor H. Premelting crystalline relaxations and phase transitions in nylon 6 and 6, 6. Macromolecules 1991;24:3215-20.

[34] Kohan MI. Nylon plastics handbook. Cincinnati: Hanser Publishers; 1995.

[35] Li Y, Goddard WA. Nylon 6 crystal structures, folds, and lamellae from theory. Macromolecules 2002;35:8440-55.

[36] Dencheva N, Nunes T, Oliveira MJ, Denchev Z. Microfibrillar composites based on polyamide/polyethylene blends. 1 . Structure investigations in oriented and isotropic polyamide 6. Polymer (Guildf) 2005;46:887-901. http://dx.doi.org/10 1016/j.polymer.2004.11.105.

[37] Samon JM, Schultz JM, Hsiao BS. Study of the cold drawing of nylon 6 fiber by insitu simultaneous small-and wide-angle X-ray scattering techniques. Polymer (Guildf) 2000;41:2169-82.

[38] Dencheva N, Denchev Z, Oliveira MJ, Funari SS. Relationship between crystalline structure and mechanical behavior in isotropic and oriented polyamide 6. J Appl Polym Sci 2007;103:2242-52. http://dx.doi.org/10.1002/app.25250. 